\title{
Coevolution of hytrosaviruses and host immune responses
}

Henry M. Kariithi ${ }^{1,2,6^{*}}$, Drion G. Boucias ${ }^{3}$, Edwin K. Murungi ${ }^{4}$, Irene K. Meki ${ }^{2,5}$, Güler Demirbaş-Uzel ${ }^{2}$, Monique M. van Oers ${ }^{5}$, Marc J. B. Vreysen², Adly M. M. Abd-Alla ${ }^{2}$ and Just M. Vlak ${ }^{5}$

\begin{abstract}
Background: Hytrosaviruses (SGHVs; Hytrosaviridae family) are double-stranded DNA (dsDNA) viruses that cause salivary gland hypertrophy (SGH) syndrome in flies. Two structurally and functionally distinct SGHVs are recognized; Glossina pallidipes SGHV (GpSGHV) and Musca domestica SGHV (MdSGHV), that infect the hematophagous tsetse fly and the filth-feeding housefly, respectively. Genome sizes and gene contents of GpSGHV ( 190 kb; 160-174 genes) and MdSGHV ( 124 kb; 108 genes) may reflect an evolution with the SGHV-hosts resulting in differences in pathobiology. Whereas GpSGHV can switch from asymptomatic to symptomatic infections in response to certain unknown cues, MdSGHV solely infects symptomatically. Overt SGH characterizes the symptomatic infections of SGHVs, but whereas MdSGHV induces both nuclear and cellular hypertrophy (enlarged non-replicative cells), GpSGHV induces cellular hyperplasia (enlarged replicative cells). Compared to GpSGHV's specificity to Glossina species, MdSGHV infects other sympatric muscids. The MdSGHV-induced total shutdown of oogenesis inhibits its vertical transmission, while the GpSGHV's asymptomatic and symptomatic infections promote vertical and horizontal transmission, respectively. This paper reviews the coevolution of the SGHVs and their hosts (housefly and tsetse fly) based on phylogenetic relatedness of immune gene orthologs/paralogs and compares this with other virus-insect models.

Results: Whereas MdSGHV is not vertically transmitted, GpSGHV is both vertically and horizontally transmitted, and the balance between the two transmission modes may significantly influence the pathogenesis of tsetse virus. The presence and absence of bacterial symbionts (Wigglesworthia and Sodalis) in tsetse and Wolbachia in the housefly, respectively, potentially contributes to the development of SGH symptoms. Unlike MdSGHV, GpSGHV contains not only host-derived proteins, but also appears to have evolutionarily recruited cellular genes from ancestral host(s) into its genome, which, although may be nonessential for viral replication, potentially contribute to the evasion of host's immune responses. Whereas MdSGHV has evolved strategies to counteract both the housefly's RNAi and apoptotic responses, the housefly has expanded its repertoire of immune effector, modulator and melanization genes compared to the tsetse fly.

Conclusions: The ecologies and life-histories of the housefly and tsetse fly may significantly influence coevolution of MdSGHV and GpSGHV with their hosts. Although there are still many unanswered questions regarding the pathogenesis of SGHVs, and the extent to which microbiota influence expression of overt SGH symptoms, SGHVs are attractive 'explorers' to elucidate the immune responses of their hosts, and the transmission modes of other large DNA viruses.
\end{abstract}

Keywords: Hytrosaviridae, Musca domestica, Glossina spp., Symbionts, Muscavirus, Glossinavirus, Apoptosis, RNAi, miRNA

\footnotetext{
* Correspondence: henry.kariithi@kalro.org; henri.muriuki@gmail.com

${ }^{1}$ Biotechnology Research Institute, Kenya Agricultural and Livestock Research

Organization, P.O Box 57811, Kaptagat Rd, Loresho, Nairobi 00200, Kenya

${ }^{2}$ Insect Pest Control Laboratory, Joint FAO/IAEA Division of Nuclear

Techniques in Food and Agriculture, Wagrammer Straße 5, A-1400 Vienna,

Austria

Full list of author information is available at the end of the article
}

(c) International Atomic Energy Agency; licensee BioMed Central Ltd. 2018 This is an open access article distributed under the terms of the Creative Commons Attribution IGO License (https://creativecommons.org/licenses/by/3.0/igo/) which permits unrestricted use, distribution, and reproduction in any medium, provided appropriate credit to the original author(s) and the source is given. 


\section{Background}

The salivary gland hypertrophy viruses (SGHVs) belong to the Hytrosaviridae [1], a relatively new family of insect double-stranded DNA (dsDNA) viruses that infect cyclorrhaphan flies with distinct ecologies and evolutionary histories. Known SGHV hosts are the hematophagous Glossina species (tsetse fly), filth-feeding Musca domestica Linnaeus (common housefly), and most probably the phytophagous Merodon equestris Fabricius (bumblebee-mimic fly) [2]. In the host, SGHV infection and replication results in the swelling of the salivary glands (SGs) and thereby producing diagnostic SG hypertrophy (SGH) syndrome [3]. SGVHs are enveloped and rod-shaped viruses that contain a single circular dsDNA genome [4-6]. Structurally, SGHVs are reminiscent of the well-studied baculoviruses [7] with which they phylogenetically form a monophyletic group together with other nuclear-replicating large dsDNA viruses such as the nudiviruses and nimaviruses [8]. Functionally however, SGHVs are readily distinguished from baculoviruses, in view of the absence of occlusion bodies, and, contrary to baculoviruses, SGHVs rarely kill their host (i.e. lower lethality) [9].

The SGHVs primarily replicate in adult flies, and cause a chronic infection that leads to reproductive dysfunctions [10]. In certain cases, such as in the tsetse fly mass-production facilities, GpSGHV can switch from asymptomatic to symptomatic infections, eliciting epizootics that decrease the flies' productivity, which can ultimately lead to the collapse of the colony [11]. Significantly, the SGHVs replicate in select host gland tissues, but no viral replication has been observed in cell lines established from homologous or heterologous insect hosts [12]. The lack of SGHV-susceptible cell/tissue cultures has hindered detailed genetic studies of SGHVs. Phylogenetically, the GpSGHV $190 \mathrm{~kb}$ genome has limited gene (open reading frame; ORF) homology to the MdSGHV $124 \mathrm{~kb}$ genome [4-6], and this formed the basis for placing these viruses in two separate genera within the family Hytrosaviridae (Glossinavirus and Muscavirus, respectively). Neither of these viruses could be placed within any of the other established dsDNA virus families $[7,13]$.

The sole member of the genus Muscavirus, the $M$. domestica SGHV (MdSGHV), infects and causes only symptomatic SGH in houseflies $[14,15]$. Topical exposure or injection of MdSGHV into adult houseflies results in overt SGH and total shutdown of oogenesis, thus inhibiting any potential for the vertical transmission of this virus $[15$, 16]. MdSGHV is globally distributed within populations of the synanthropic housefly [17], a highly mobile insect that moves several kilometers in search of feeding and oviposition sites associated with livestock keeping [18]. Sequence analysis of selected genes from different MdSGHV isolates revealed low polymorphisms between the isolates [17]. This low viral polymorphism potentially reflects the close associations of the highly gregarious domestic housefly with human movements/migrations, which may in turn influence the frequency of MdSGHV-housefly interactions. Within housefly populations, MdSGHV induces variable rates of SGH prevalence (e.g. 0-40\% in North Florida dairy farms $[19,20])$, potentially related to the fly's seasonal densities at the various sampling sites. Since natural selection favors transmission modes that provide pathogens with the greatest fitness gains [21], the highly transient housefly densities may have evolutionarily favored horizontal transmission for MdSGHV.

The Glossinavirus type species, G. pallidipes SGHV (GpSGHV) exists predominantly in an asymptomatic infection state in tsetse flies, but certain unknown (biotic and abiotic) factors can trigger development of overt SGH symptoms in apparently healthy individuals [2, 22]. Intrahemocoelic injection of GpSGHV does not induce overt SGH symptoms in the parental generation, rather, the symptoms develop in some of the $F_{1}$ progenies [23]. Contrary to the globally distributed MdSGHV, GpSGHV is specific to Glossina species, which are restricted to sub-Saharan Africa. Tsetse fly distribution is principally determined by habitat, environmental conditions and host animal dynamics. Compared to the highly mobile houseflies, tsetse flies are fairly sedentary, and make random movements of only 150$550 \mathrm{~m}$ per day [24]. Based on selected viral genes, GpSGHV has a lower polymorphism than MdSGHV $[17,25]$. Of all the Glossina species (in both field and wild conditions), it is only G. pallidipes that often exhibits overt SGH symptoms. Given that an asymptomatic (persistent) infection signifies the best adapted or most successful virus-host coevolution [26], G. pallidipes is arguably the most recent GpSGHV host, which partially explains the absence of overt SGH symptoms in other Glossina species [27].

This review evaluates the coevolution of SGHVs [4-6] and their hosts $[28,29]$. Phylogenetic relatedness is determined for the immune genes in G. pallidipes and $M$. domestic in relation to orthologs/paralogs from the model insect, Drosophila melanogaster, and the African malaria mosquito, Anopheles gambiae. Inferences are made from other virus-host systems for which the immune genes have been identified and characterized.

\section{Host-range specificity, transmission dynamics and pathogenesis of SGHVs \\ Infection dynamics of MdSGHV in houseflies}

Examination of MdSGHV-infected houseflies revealed that SGH symptoms were due to the hypertrophy of the nucleus (nucleocapsid assembly) and cytoplasm (viral membrane acquisition) of the SG cells [30]. In addition to replication in the SGs, MdSGHV undergoes limited replication in the housefly's corpora-allata/cardiaca (CA/ $\mathrm{CC})$ glands, the sites that produce neurohormones and 
juvenile hormones that regulate reproduction and metamorphosis [16]. Reverse transcriptase quantitative PCR (RT-qPCR) analysis demonstrated that replication of MdSGHV in non-glandular tissues blocked the transcription of hexamerin and yolk proteins [15].

Maintaining uninfected houseflies together with SGH-positive flies at various densities in cages with a shared food source for 10 filial generations resulted in low percentages $(\sim 10 \%)$ of SGH-positive houseflies that persist throughout the generations ( 12 weeks) [14]. Significantly, unlike the GpSGHV-Glossina system, these MdSGHV infections did not cause the collapse of the housefly populations. This virus is presumably transmitted per os amongst houseflies that feed on shared food substrates [19], but this transmission mode is apparently insufficient to sustain a high prevalence in housefly populations. In the laboratory, force-feeding newlyeclosed $(<2$ h-old) flies with MdSGHV suspensions induced overt SGH symptoms in $~ 53 \%$ of the individuals [17]. In nature however, such newly eclosed flies do not imbibe food until after several hours, which, within 12$24 \mathrm{~h}$ post-eclosion allows synthesis of the peritrophic matrix (PM) that protects the gut and allow the flies to become highly resistant to orally-ingested virus $[17,20]$. During feeding, an infected housefly regurgitates digestive fluids (including salivary secretions) onto the food substrates thereby releasing copious amounts of infectious viral particles [31]. Combined with the fact that topical virus application to older flies (resistant to per os challenge) induces overt SGH symptoms [32], these results suggests that MdSGHV is exposed to and transmitted to healthy conspecifics through the cuticle wounds when flies feed en masse at virus-contaminated sites [33]. Moreover, laboratory-produced houseflies contract MdSGHV infections when introduced into virus-contaminated fly cages [19].

The absence of both asymptomatic infection state, and lack of either vertical or sexual transmission of MdSGHV in house flies raise the question of how MdSGHV has evolved to ensure its persistence within natural fly populations, particularly during low seasonal fly densities. This question is further compounded by the absence of occlusion bodies in SGHVs, which in the case of baculoviruses facilitate long-term survival of baculoviruses outside of their hosts. Potentially, the insect saliva in combination with released contents of the insects' crop organ stabilizes the MdSGHV particles released during the feeding events. Cage studies have shown that the MdSGHV maintains a low frequency of infection over multiple fly generations [14]. In nature, the gregarious nature and high densities of houseflies in animal farms provide an avenue for increased exposure of flies to MdSGHV infections (via cuticle); such an exposure is a requisite for the maintenance of this virus in the fly populations. Alternatively, MdSGHV may reside asymptomatically in reservoir hosts, providing an additional avenue for virus maintenance. For example, under laboratory conditions, other muscids such as the obligate hematophagous stable fly (Stomoxys calcitrans), a larval predator of the housefly, and the black dump fly (Hydrotaea aenescens), support limited viral replication but without concomitant expression of overt SGH symptoms [32, 34]. Whether these or other muscids that occur sympatrically with the housefly can transmit infectious MdSGHV particles to healthy houseflies remains to be tested. It should be noted that tsetse fly species exhibit resistance to MdSGHV injections.

\section{Infection dynamics of GpSGHV in tsetse flies}

Different Glossina species show wide variations in their susceptibilities to GpSGHV infection. Using six Glossina spp. derived from laboratory colonies, Demirbas-Uzel et al. [35] recently showed that G. pallidipes and G. brevipalpis were the most susceptible and refractory to the virus, respectively. Meki et al. [27], observed that $15 \%$ of wild-caught G. brevipalpis had asymptomatic GpSGHV infections as compared with $0-100 \%$ of asymptomatic infections in different G. pallidipes populations. Moreover, whereas only one GpSGHV haplotype infected G. brevipalpis flies, G. pallidipes harbored 13 different haplotypes [27]. Hypothetically, GpSGHV can be horizontally transmitted in the wild when cohorts of flies feed on the same wild animal [27], but it is unclear whether different tsetse species in the wild populations feed together on the same animal. In the normal type of feeding on an animal host, tsetse flies typically exhibit 'poolfeeding' whereby they lacerate blood capillaries, resulting in hemorrhage, which is rapidly imbibed [24]. After the flies cease feeding, small blood pools form around the capillaries, which if the deposited saliva contains infectious viral particles, other flies may become infected, thus aiding in virus dissemination within fly populations. In comparison, a non-systemic virus transmission mode through co-feeding on aviremic, non-clinical vertebrate hosts has been demonstrated for the vesicular stomatis virus in the striped black fly, Simulium vittatum [36]. However, most examined tsetse species display asymptomatic infections, and the number of virus particles deposited during feeding is much lower $\left(\sim 10^{2}\right.$ viral genome copies) as compared with the levels deposited by symptomatic flies ( $\sim 10^{6}$ genome copies) [22]. In any case, the dynamics of GpSGHV transmission probably depend on the feeding behavior of individual Glossina species, their feeding preferences, feeding time, proximity (in terms of time and space) of uninfected flies to infected flies, and the susceptibility to virus infection within the particular fly populations. On this note, it is known that for some tsetse species such as G. pallidipes 
living in the same habitat, each animal host (e.g. bovids) can support feeding of more than 1000 flies, with each host giving almost 300 blood meals daily [37].

The long-lived (120-150 days) solitary tsetse fly has a life history distinct from the short-lived (15-30 days) gregarious housefly, which may influence virus transmission. Tsetse flies reproduce by adenotrophic viviparity and females retain fertilized eggs, and feed larvae with intrauterine "milk" produced by the milk glands, which are highly modified accessory glands [38]. Females give birth to fully mature third-instar larvae, that upon larviposition burrow into soil and pupate within few hours $[39,40]$. Under laboratory conditions, GpSGHV is transmitted horizontally and vertically [22], and in G. pallidipes females, the virus undergoes limited replication in the milk gland cells providing a conduit for its ingress into developing larvae/ pupae [23]. Adults of the $F_{1}$ G. pallidipes produced by virus-injected mothers display high prevalence of SGH and reproductive dysfunctions.

Recent data have indicated that when GpSGHV is injected into the third-instar larvae of G. pallidipes, the adults that develop from these larvae and their subsequent $F_{1}$ progenies release negligible amounts of infectious viral particles via saliva during feeding [41]. These observations suggest that the balance between vertical and horizontal transmission in general is associated with significant changes in virulence of several pathogens [21]. For example, promotion of vertical over horizontal transmissions made bacteriophages less virulent [42]. Another example is the selection for reduced pathogenesis observed in the cucumber mosaic virus, after vertical serial passages in Arabidopsis thaliana, but not following horizontal passages [43]. Similarly, when subjected to long-term vertical transmission in its Paramecium host ( $>800$ host generations), the parasitic bacterium Holospora undulata lost infectivity when shifted to horizontal transmission [44].

Within laboratory-bred and wild tsetse populations, GpSGHV typically causes asymptomatic infections [25]. There is much debate whether the GpSGHV asymptomatic infection represents a sublethal, persistent infection state, or it is a truly latent state. During persistent infections, a virus remains in specific cells of infected individuals, and is accompanied by a perpetual low-level production of virions, but without excessive cellular damages [45]. During a latent infection, viral genomes and proteins are present in infected cells for a certain period, but without demonstrable formation of infectious viral particles [26]. Notably, a virus can cause both persistent and latent infections in the same host at the same time, but in different cells or tissues, which may or may not be dictated by the tissue tropism of the virus $[26,45]$. It is speculated that during asymptomatic infections, GpSGHV exists in both persistent and latent infection states at the same time. For instance, the release of low amounts of virus $\left(\sim 10^{2}\right.$ viral genome copies) via saliva during feeding by an asymptomatic fly [22] supports GpSGHV persistent infection state in the SG cells, i.e. the virus replicates at such low levels that small amounts of viral particles are produced in the SGs without development of overt SGH symptoms. At the same time, the virus may latently infect non-salivary gland tissues in which viral DNA is detectable but no transcripts, for instance in the tracheal cells [3]. In both cases, the virus does not induce SGH symptoms or reproductive dysfunctions [22].

It is unlikely that SGHVs integrate into host genomes as proviruses, since using GpSGHV genes as probes did not indicate such integration. Maintenance of asymptomatic tsetse flies at high densities in fly holding cages and feeding the flies using the in vitro membrane feeding technique, as applied in mass-rearing facilities and some laboratories, increases opportunities for flies to imbibe infectious viral particles released via saliva [46]. Over time, the increased viral titers induce SGH that results in release of increased virus particles leading to additional symptomatic infections culminating in SGH epizootics that can destroy entire fly colonies $[2,6,11]$. Laboratory assays have demonstrated that GpSGHV delivered orally or by injections into asymptomatic (or uninfected) females increased virus titers, but did not induce SGH symptoms or reproductive dysfunctions $[23,35]$. Examination of the SGs from symptomatic $F_{1}$ progeny revealed that unlike the MdSGHV that induces both nuclear and cellular hypertrophy (enlarged cells incapable of replication), GpSGHV induces cellular hyperplasia (enlarged cells capable of replication) resulting in the observed SGH symptoms $[2,16]$.

Compared to MdSGHV, the asymptomatic (or persistent) infection is potentially advantageous to GpSGHV by ensuring transmission and maintenance of progeny virus over a long period of time (fly-to-progeny) [23]. The asymptomatic infection could facilitate multiple infections by lineages of the same virus or different viruses, thus leading to viral complexity and evolution of novel virus haplotypes because these may confer to the virus competitive fitness advantage to survive in the host. Lastly, by not inducing disease in the asymptomatically infected individuals, the virus can be transmitted horizontally (intra- and inter-species) via salivary secretions to other flies, particularly under laboratory settings where several tsetse fly species feed on the same feeding membrane, and thus maintained within the fly populations. In view of these advantages, one could conclude that GpSGHV has evolutionarily selected asymptomatic infection as a survival strategy. 


\section{The reciprocal tripartite SGHV-host-symbiont interactions}

Symbiont-mediated 'priming' of the host immune system Insects with restricted diets such as the hematophagous tsetse flies and the plant sap-feeding aphids, are furnished with specialized mycetomes containing symbionts that synthesize essential nutrients or digest and detoxify ingested foods. Tsetse flies harbor, depending on the species, a unique community of three bacterial symbionts, i.e. Wigglesworthia, Soldalis, and Wolbachia [47]. Similar to GpSGHV, the three symbionts are maternally transmitted transovarially or via the milk gland secretions to the developing larva [23, 47, 48]. Houseflies on the other hand, appear to be either devoid or possess low densities of the symbionts found in the tsetse flies. Bahrndorff et al. [49] detected Wolbachia infections in less than $4 \%$ of $M$. domestica females collected from 10 widely distributed farms in Denmark. Perhaps the low Wolbachia densities are transiently associated with the housefly, and are without any perceptible functional significance.

The presence and densities of these symbionts can influence the immune competence of the host [50]. For example, Wolbachia upregulates at various levels the transcription of immune genes upstream of several pathways (e.g. Imd, Toll, JNK, RNAi, JAK/STAT, autophagy, phagocytosis, melanization, etc.) in mosquitoes, Drosophila, silkworms, and some parasitoid wasps [51, 52]. Wolbachia also mediates strain-dependent protection of Drosophila against infections with the Drosophila C virus (DCV), flock house virus (FHV) and cricket paralysis virus (CrPV) $[53,54]$ as well as some mosquito viruses [55]. Wolbachia is presumed to facilitate its own persistence and maintain its close association with the host insect by modulating the immune responses of the insect hosts [56]. The Wolbachia-modulated immune effectors include cecropins, defensins, thioester-containing proteins (TEPs), C-type lectins (CTLs), reactive oxygen species (ROS), relish 1 (REL1), Spätzle 1A (Spz1A), and attacins [57, 58]. Stable introduction of some Drosophila-derived Wolbachia strains into Aedes aegypti primed immune effector genes in the transinfected mosquito, and consequently increased Wolbachia replication [59]. The increased Wolbachia titers interfered with pathogenesis and/or dissemination of dengue virus (DENV) in the transinfected Ae. aegypti. In another study, resident Wolbachia improved refractoriness of Culex quinquefasciatus and D. melanogaster to West Nile virus (WNV) infections by significantly reducing the viral titers and transmission during feeding compared to their $\mathrm{Wol}$ bachia-free counterparts [60]. However, Wolbachia can also shift the balance towards the virus in virus-host interactions. For instance, Wolbachia enhanced the susceptibility of the African armyworm Spodoptera exempta to infection by $S$. exempta nucleopolyhedrovirus (SpexNPV) and increased SpexNPV-induced mortality [61]. Is should however be noted that in addition or alternative to direct priming of the insect's immunity, Wolbachia could also indirectly impact on the viral titers in the host. For example, Wolbachia could reduce viral replication by competing for cellular space and resources [62], a scenario which could assist the host's immune system to suppress replication of remnant progeny viruses. Alternatively, Wolbachia could affect the vesicular transport apparatus within the infected cell that are required for viral trafficking within the infected cell cytoplasm, or produce certain molecules (e.g. via its type IV secretion system) that may directly impede the virus [63]. This is particularly due to the overlapping tissue tropism between the virus and the symbiont, and the potentially strong natural selection pressure for the two organisms to increase their chances for maternal transmission [23, 64].

Wigglesworthia does not directly confer pathogen resistance to its tsetse host, but is required for maturation during larval development and for proper functioning of the immune system in adult tsetse flies $[50,65]$. The role of Sodalis in tsetse is largely unclear, but certain Sodalis genotypes are postulated to enhance both the tsetse's susceptibility to trypanosome infections and its innate vectorial competency for transmission of the parasites [66] via a complex of biochemical mechanisms. Moreover, Sodalis produces many enzymes that impact various host metabolic and biosynthetic processes such as nutrient uptake, cellular transport, protein folding, and redox metabolism [67]. One could therefore logically infer that, Sodalis indirectly influences the outcomes of virus infection.

\section{Correlation between symbiont densities and SGH prevalence}

The absence (or low densities) of Wolbachia is thought to contribute to the expression of SGH symptoms in laboratory-bred G. pallidipes colonies as compared with other Glossina species that usually do not show overt SGH symptoms [23]. In protective Wolbachia-host combinations, high densities of the Wolbachia, and the frequency with which this symbiont is maternally inherited are a prerequisite $[68,69]$. Although up to $100 \%$ of tsetse flies in laboratory colonies can be Wolbachia-infected, the prevalence of infection significantly varies amongst wild tsetse populations. Doudoumis et al. [70] observed that Wolbachia prevalence varied among tsetse species, i.e. $100 \%$ and $90-100 \%$ in laboratory and wild G. $m$. morsitans, respectively, $100 \%$ in laboratory G. $m$. centralis, $52-100 \%$ in wild G. austeni, $2-41 \%$ in wild G. brevipalpis, $0.3 \%$ and $0-8.5 \%$ in laboratory and wild $G$. pallidipes, respectively, and $0 \%$ and $0-8.3 \%$ in laboratory and wild G. p. gambiensis, respectively. Wolbachia was not detectable in wild and laboratory populations of $G$. p. palpalis, G. f. fuscipes and G. tachnicoides. 
Although the correlation between Wolbachia densities and the SGH incidence is yet to be experimentally demonstrated, data from various studies from laboratory-bred and field-collected Glossina spp., implicate a species-specific relationship between the occurrence of SGH and Wolbachia infections. For instance, whereas Wolbachia prevalence is high in various laboratory-bred colonies of G. m. morsitans and G. $m$. centralis (100\%) and G. brevipalpis (41.2\%) [70], there is no demonstrable evidence for the occurrence of overt SGH symptoms in these three Glossina species. However, this apparent inverse Wolbachia-Glossina relationship differs from some laboratory-bred Glossina species (e.g. G. palpalis, G. p. gambiensis and G. f. fuscipes) that have undetectable Wolbachia infections symptoms [70, 71] and so far, there is no evidence for the occurrence of overt SGH. It should be noted that despite the absence of diagnostic SGH symptoms, the above-mentioned species are susceptible to various degrees to GpSGHV infections, regardless of whether the infections are natural or artificial (intra-hemocoelic injections) $[25,27,35]$. On the other hand, laboratory-bred G. pallidipes flies, which typically exhibit overt SGH symptoms and high prevalence of GpSGHV (up to 100\%) appear to be either Wolbachia-free [23, 72], or harbor extremely low densities of this symbiont $[70,71]$.

\section{Impact of symbionts on tsetse susceptibility to GpSGHV infections}

Antibiotic-mediated suppression of the Wigglesworthial Sodalis complex in G. pallidipes reduces vertical transmission of GpSGHV and inhibits development of overt SGH symptoms in $F_{1}$ progeny [23]. Significantly, laboratory $G$. pallidipes flies do not have detectable Wolbachia, thus precluding verification of its effects on GpSGHV pathogenesis and transmission [23]. However, Wolbachia densities in the DENV-A. aegypti-Wolbachia system are extremely low in mosquito midguts, fat bodies and SGs, which correlates with a lack of resistance to DENV infections as compared to the DENV-resistant $A$. aegypti that harbors high Wolbachia densities [73]. The Wolbachia-mediated virus resistance in mosquitoes and Drosophila is observed in Wolbachia-transinfected hosts, i.e. species infected with native Wolbachia strains do not typically show a virus-resistant phenotype, but the native strains still confer their hosts with antiviral responses [60, 74-76]. The lack of immune-priming could be due to co-evolutionary trade-offs between the symbionts and the host's immune system as well as other life-history traits [77]. It is therefore possible that the low Wolbachia densities in G. pallidipes increases its susceptibility to GpSGHV infections.

Impacts of symbiont deficiency in housefly susceptibility to MdSGHV infections

Despite the absence (or titers that are too low to be detectable) of symbionts in the housefly, this insect passively harbors highly diverse non-symbiotic microbiota that are environmentally acquired and that vary significantly between individuals [49]. Compared to Drosophila, the housefly genome contains a substantial increase in the repertoire of genes involved in immune-related pathways [29], many of which are significantly upregulated during MdSGHV infections [16]. It therefore seems that the housefly has complemented its symbiont deficiency by evolving structural, biochemical, and behavioral mechanisms that serve as barriers to opportunistic pathogen infections. Additionally, non-symbiotic bacteria may manipulate oviposition behaviors of the house fly via volatiles produced by bacteria on conspecific eggs $[78,79]$. This may impact the fly's population dynamics, and thus indirectly impact MdSGHV infections. The symbiont-mediated reduction of pathogen proliferation in dipterans implies that the absence or presence of low densities of symbionts potentially influences the occurrence of only symptomatic MdSGHV infections and the high virus prevalence amongst housefly populations. Further, the housefly-associated microflora may directly correlate to the fly's nutritional ecology and physiology [80], i.e. the housefly has significantly lower energy consumption compared to the relatively higher energy consumption associated with the specialized metabolism of tsetse flies [24].

\section{The 'arms-race' between SGHVs and their dipteran hosts}

Evolution favors hosts that develop strategies to avoid or limit pathogen infections, and pathogens that develop effective mechanisms to evade the host's anti-viral defenses. This 'arms-race' results in a stable but dynamic equilibrium (homeostasis) between a virus and its host [81], whereby the virus does not significantly compromise the host's reproductive capacities, nor does the host's immune system completely block production of virus progeny. In addition to the host immune pathways, non-immune responses such as cell-cycle control and signaling, are also involved in the establishment of the virus-host homeostasis at the cellular level [82]. Modulation of the non-immune pathways hinges on the dependency of viruses on the host's machinery for gene expression [83], which can be regulated at the levels of transcription, protein turn-over, or transport of viral gene products and host's transcription factors to viral replication sites within infected host cells.

\section{Host immune responses and SGHVs survival}

The first line of insect's defense is the physical barrier provided by the cuticle and the PM of the gut, in addition to, low $\mathrm{pH}$, digestive enzymes and ROS it produces [84, 85] and various antimicrobial peptides (AMPs) that block the pathogen's ingress/replication [86]. When breaching these defense barriers, pathogens elicit both cellular and humoral innate defenses within 
the insect body [84]. Known anti-viral responses in insects are largely elicited by the mere presence of virus-derived dsRNAs (RNAi-mediated degradation of viral genomes [87-89]), and by virus-induced cellular damages (via the Jak/STAT, Toll and Imd pathways [9093]). Many of the genes in these pathways are significantly upregulated in SGHVs infections [16, 94-96].

Once established, the outcome of virus infection, whether acute or chronic, depends on the balance between the speed of viral replication/dissemination and the efficiency of the host's immune responses. As a counter-defense, large dsDNA viruses possess many genes that can manipulate host immune responses [97]. These viruses have evolved to maximize their replication within the host by 'acquiring and customizing' strategic host genes to mimic, block and/or regulate key cellular processes, that confuse the host's immune system and that enhance their dissemination. This 'camouflage and sabotage' paradigm is evolutionary advantageous to dsDNA viruses whose large and rather rigid genomes do not allow the high adaptive mutation rates associated with viruses containing smaller/single dsDNA or RNA genomes [98].

The GpSGHV virions incorporate several host-derived proteins, some of which potentially assist in evading the host's immune system [95]. It is unclear whether MdSGHV virions incorporate host proteins. Unlike MdSGHV, GpSGHV appears to have recruited into its genome several cellular genes from its ancestral hosts during its evolution. The inheritance of host genes by the GpSGHV implies its long evolutionary relationship with the tsetse flies allowing the virus to construct a large genome that partially accounts for its dimorphic life style. On the other hand, the relatively smaller MdSGHV genome $(120 \mathrm{~kb})$ probably indicates that the housefly virus has not acquired as many genes (via horizontal gene transfer) as has GpSGHV (190 kb). Alternatively, MdSGHV may have had a longer evolutionary time with its host the housefly than GpSGHV with tsetse, in which case MdSGHV may have lost redundant genes. A third alternative explanation is that MdSGHV may have gained higher efficiency than GpSGHV in targeting beneficial host genes during infection so that a larger genome became evolutionary unnecessary.

\section{The host RNAi machinery and the SGHV's evolutionary mechanisms}

RNA interference (RNAi) is recognized as a conserved anti-viral defense mechanism in insects (and plants) that is not only active against RNA viruses but also against several groups of large dsDNA insect viruses (ascovirus, baculovirus, iridovirus and nudivirus) [99, 100]. RNAi involves short interfering RNAs (siRNAs; derived from exogenous dsRNA), and microRNAs (miRNAs; encoded by the host or viral genome), which interfere with gene expression by targeting specific mRNAs [101]. There is evidence for the presence and functionality of RNAi machinery against dsDNA viruses in flies, including the presence of the key genes in RNAi pathway (Dicer-2 and Argonaute-2), and flies (e.g. Drosophila) with loss-of-function for these two genes are reported to be highly susceptible to viral infections [87, $88,100,102]$. There are indications that both $D c r-2$ and Ago-2 genes are not only expressed in tsetse flies, but are also significantly up-regulated in SGH symptomatic flies as compared with asymptomatic flies [103]. In the case of MdSGHV, at least two isoforms of Ago-2 and Dcr-1 genes were up-regulated in viremic females compared to their uninfected conspecifics [16]. Together, these data imply that the RNAi pathway may be actively involved in the dynamics of the SGHV-Musca/Glossina system.

The DNA virus-encoded RNAs are thought to act in a similar version to the host transcription factors and as such, they co-opt specific host gene pathways by destroying (e.g. in herpesvirus saimiri; HVS), boosting (e.g. in Epstein-Barr virus; EBV), or hijacking (e.g. in human cytomegalovirus; HCV) host miRNAs to reshape the cellular environment to the benefit of viral replication [104]. More importantly, due to their ability to attenuate the host immune responses, the virally-encoded miRNAs have been implicated in the reactivation of some viruses from latency [105]. During viral latency/ persistence, only minimal numbers of genes are expressed to evade the host immune system [106, 107]. Examples of viral miRNAs involved in the latent/persistent virus infections include miR-H2-3p and miR-H6 (herpes simplex virus 1; HSV-1), miR-UL112-1 (HCMV), and miR-K5 (Kaposi's sarcoma-associated herpesvirus; KSV) [108]. In some cases, certain viral miRNAs repress global expression of viral genes, for instance via epigenetic modifications of viral genomes [109, 110]. Significantly, it is more economical for viruses to evolve miRNAs targeting (complementary to) specific host mRNAs than it is to evolve novel regulatory genes. Besides, the small sizes of miRNAs $(<200$ nucleotides) do not pose size constraints on viral genomes.

In a genome-wide screen, Garcia-Maruniak et al. [13] identified six and seven miRNAs in the genomes of MdSGHV and GpSGHV, respectively. Although the presence of miRNA encoding sequences in the SGHVs were predicted in silico, it is likely that these miRNAs are functional. This is particularly so in the case of GpSGHV, which can switch from asymptomatic to symptomatic infections $[2,23]$, a transition that potentially depends on subtle differences in miRNA-mediated viral gene expression. In view of the subtlety of miRNA-mediated gene regulation, virus-encoded miRNAs may have reduced roles during MdSGHV symptomatic infection whereby robust viral and host gene expression may be dominant, despite the presence of miRNAs in infected cells. Our 
contention here is based on the currently known repertoire of viral miRNA $(n>200)$ [111], whose putative functions (e.g. prolonging lifespan of infected cells, regulating virus and/or host genes expression to limit symptomatic infections, etc.) suggest that most of these miRNAs may facilitate viral latency/persistence. In this case, GpSGHV is more likely than MdSGHV to utilize miRNAs. It is important to note that, the RNAi machinery merely minimizes, but does not eliminate viral infections. It is not clear why this is the case. However, adoption of alternative or additional layers of anti-viral mechanisms by insects may have made it unnecessary to invest in the optimization of RNAi and associated pathways. In summary, one could question the impacts of RNAi on MdSGHV infection in the housefly (exclusively symptomatic), as compared to GpSGHV infection in tsetse fly (predominantly asymptomatic).

\section{Evolution of host's apoptosis and SGHVs escape strategies}

In their hosts, viruses from diverse families induce apoptosis, a biochemically and genetically-regulated cell suicide process [112]. Apoptosis is an important pillar of the host's innate immune response aimed to limit the time and host's cellular machinery available for viral replication and dissemination [113]. Viruses cause apoptosis due to their inhibition of the synthesis of host proteins, which disrupts the balance between the synthesis and degradation of apoptosis inhibitors and activators/initiators. This imbalance results in the increase of the activators over the inhibitors thereby promoting apoptosis [114]. However, in some cases (e.g. influenza and sindbis virus; SINV), apoptosis can facilitate virus replication and dissemination [115]. In such cases, the virusinduced apoptotic response results in pinching off of virus-containing apoptotic bodies, which are subsequently phagocytosed by neighboring (uninfected) cells thus facilitating virus dissemination within the host without eliciting immune response [116].

Apoptosis is initiated and executed by cysteine-dependent aspartate-specific proteases (caspases) upon activation by apoptotic stimuli. Activated caspases consequently cleave their target substrates (e.g. protein kinases, signal transduction proteins, chromatin modifiers, DNA repair enzymes, inhibitory endonucleases, etc.) [117]. The model organism, Drosophila, encodes seven caspases (See Table 1 and the references thereof) $[118,119]$. These include three apoptosis initiators - death regulator Nedd2-like caspase (DRONC/caspase-9), death-related ced-3/Nedd2 (DREDD/Caspase-8), and serine/Threonine-rich caspase-A (STRICA), in addition to four effectors - death associated molecule related to Mch2 (DAMM), Drosophila interleukin-1 $\beta$-converting enzyme (DrICE), death executioner caspase-related to Apopain/Yama (DECAY/Caspase-3/7), and death caspase protein 1 (DCP-1)
[120]. Several caspases have also been reported in mosquitoes (Ae. aegypti and An. gambiae), the red flour beetle (Tribolium castaneum), and the pea aphid (Acyrthosiphon pisum) [117]. Apoptosis in Drosophila is activated by DRONC, and dampened by Drosophila inhibitor of apoptosis protein 1 (DIAP1). DIAP1 directly binds to two of the four effectors (i.e. DCP-1 and DrICE) to block their substrate-cleavage activities, and promotes ubiquitination of DRONC [119]. DREDD is essential for activation of the innate immune responses (via cleavage of Relish, a NF- $\mathrm{kB}$ family member of the Imd pathway); DREDD activity is dampened by Defense repressor-1 (Dnr1) protein [121]. The upregulation of DAMM upon DCV infections in Drosophila [91] suggests involvement of apoptosis in DCV infection, potentially via the JAK/STAT pathway.

Using the seven Drosophila caspase sequences as baits, we searched various databases for M. domestica and Glossina spp., caspase homologs and performed phylogenetic analyses using the conserved caspase domains (Fig. 1). The three initiator caspases (DREDD, DRONC and STRICA) clustered into distinct clades in the three dipterans (Fig. 1a). Glossina species had single copies of DREDD and DRONC, but the two initiator caspases were duplicated in M. domestica. STRICA was evidently duplicated in both Glossina spp., and $M$. domestica pointing to putative adaptive evolution of this caspase. For the effector caspases, Glossina and M. domestica DAMM delineated into distinct orthologous clusters (Fig. 1b). Glossina DECAY caspases formed a distinct cluster closely related to the DCP-1 cluster into which $M$. domestica DECAY segregated. The $M$. domestica DECAY was apparently duplicated. All the $M$. domestica DCP-1 segregated together with DrICE caspases (Fig. 1b). Together, the analyses showed widespread duplication of M. domestica caspases as compared with their Glossina spp. homologs. The conservation of the caspases in Glossina and $M$. domestica imply functional conservation. We have recently reported that the caspase-8 (DREDD) homolog (essential for activation of innate immune response), caspase-3 (DECAY) homolog (apoptosis effectors), and Relish, were upregulated in viremic females compared to control houseflies [16].

To prolong infected cell viability and facilitate virus replication under the threat of apoptosis, viruses have evolutionary devised multiple mechanisms to inhibit apoptosis; these mechanisms mimic key regulators of apoptosis [122]. There are four main protein families of viral inhibitors of apoptosis, i.e. serpins, baculovirus P35 (and P49; P33), inhibitors of apoptosis (IAPs), and viral FLICE-inhibitory proteins. Three of these are well-known in large dsDNA insect viruses, i.e. P35 of the baculovirus Autographa californica MNPV (AcMNPV), its P49 homolog in Cydia pomonella granulovirus (CpGV), and the IAPs as present in Orgia pseudotsugata SNPV, CpGV [123] and many other baculoviruses. During infection in vertebrates, the baculovirus P33 
Table 1 Apoptotic and/or immunity-related roles of Drosophila caspases

\begin{tabular}{|c|c|c|c|}
\hline Drosophila caspase & $\begin{array}{l}\text { GenBank Acc. } \\
\text { No. }\end{array}$ & Apoptotic and, (or anti-viral roles in insects & Refs. \\
\hline \multicolumn{4}{|l|}{ Apoptosis Initiators } \\
\hline $\begin{array}{l}\text { Death regulator Nedd2-like caspase (DRONC); Caspase-9 } \\
\text { homolog }\end{array}$ & NP_524017.1 & $\begin{array}{l}\text { Ecdysone-induced (developmental and stress-induced } \\
\text { apoptosis); }\end{array}$ & {$[108,170]$} \\
\hline $\begin{array}{l}\text { Death-related ced-3/Nedd2 (DREDD) or DCP-2; Caspase-8 } \\
\text { homolog }\end{array}$ & NP_477249.3 & $\begin{array}{l}\text { Essential for activation of innate immune signaling } \\
\text { (activates Relish of the Imd pathway) }\end{array}$ & {$[108,171]$} \\
\hline $\begin{array}{l}\text { Serine/Threonine-rich caspase-A (STRICA) or Downstream } \\
\text { regulatory element-antagonist modulator (DREAM) }\end{array}$ & NP_610193.1 & $\begin{array}{l}\text { Together with DRONC, STRICA activates DCP-1 and } \\
\text { DRICE }\end{array}$ & {$[172]$} \\
\hline \multicolumn{4}{|l|}{ Apoptosis Effectors } \\
\hline Death associated molecule related to Mch2 (DAMM) & AAF82437.1 & Upregulated in DCV-infected Drosophila & [92] \\
\hline Death caspase protein 1 (DCP-1) & NP_476974.1 & $\begin{array}{l}\text { Essential for germ-line apoptosis in mid-oogenesis; } \\
\text { cleaves P35 }\end{array}$ & {$[172]$} \\
\hline $\begin{array}{l}\text { Death executioner caspase-related to Apopain/Yama } \\
\text { (DECAY); Caspase-3, ( } 7 \text { homolog }\end{array}$ & NP_477462.1 & $\begin{array}{l}\text { Involved in developmental apoptosis and immunity; } \\
\text { (upregulated in DENV-infected mosquito) }\end{array}$ & $\begin{array}{l}{[111,171,} \\
173]\end{array}$ \\
\hline Drosophila interleukin-1 $\beta$-converting enzyme (DrlCE) & NP_524551.2 & $\begin{array}{l}\text { Required for baculovirus-induced apoptosis; inhibited } \\
\text { by the baculovirus P35/ P49/CrmA }\end{array}$ & [131] \\
\hline
\end{tabular}

(encoded by AcMNPV orf92) is involved in processes such as cell-cycle regulation, apoptosis, differentiations and oncogenic transformations [124]. P35-mediated inhibition of the evolutionary conserved ICE/ICE-like proteases [125] results in increased AcMNPV titers and allows successful virus infection in the host [126]. Neither MdSGHV nor GpSGHV encodes P35 or P49 homologs, which probably underscores the functional and evolutionary differences between SGHVs and baculoviruses. Further, SGHVs do not have homologs to baculovirus genes known to induce global protein synthesis shutdown, i.e. the host range factor-1 (HRF-1; Lymantria dispar MNPV), the host cell-specific factor-1 (HCF-1; AcMNPV), and the EP32 (Hyphantria cunea MNPV) [127]. However, MdSGHV encodes a single copy of IAP (MdSGHV078) [29] and iap transcripts are moderately enriched in viremic flies [16]. GpSGHV does not encode IAPs. The IAPs prevent apoptosis by acting at the evolutionary conserved signaling phase in the apoptotic pathway, i.e. block caspase activation [128]. IAPs prohibit apoptosis either via ubiquitination of host's pro-apoptotic proteins (Grim, Reaper, HID and Sickle), or via direct interactions with caspases $[129,130]$, and may therefore act upstream of P35 or use the same targets.

We phylogenetically analyzed the MdSGHV IAP versus homologs reported in OpMNPV, Spodoptera exigua MNPV (SeMNPV), Epiphyas postvittana NPV (EppoNPV), and Bombyx mori NPV (BmNPV), Buzura suppressaria NPV (BusuNPV), CpGV, Chilo iridescent virus (CIV) and African swine fever virus (AsFV) (see Table 2). The MdSGHV IAP clustered with IAPs from AsFV and CIV (Fig. 2a). Compared to the domains of the IAPs from the other viruses, the MdSGHV, AsFV and CIV IAPs contained one BIR domain and an additional RING domain (Table 2; compare with Fig. 2b). Although cellular IAPs contain up to three tandem copies of the BIR domain, viruses contain one or two BIRs; a single BIR domain is sufficient for suppression of apoptosis [131]. The distinct domain organization within the IAPs potentially points to evolution by independent reductive changes from a larger ancestral sequence with complicated domain organization. It is also important to note that the housefly genome encodes for the proapoptotic proteins (Grim, Reaper, and HID) [29]. These data imply that during MdSGHV symptomatic infection, apoptosis does occur in the housefly, but that MdSGHV controls and alters progression of apoptosis to the benefit of the virus, i.e. to ensure that the infected cells do not only survive but also simultaneously grow and efficiently produce progeny virus. These events, combined with the multiple fronts employed by MdSGHV to manipulate host's antiviral responses, may contribute to development of SGH symptoms.

The apparent lack of anti-apoptotic gene homologs in GpSGHV suggests that this virus may follow alternative strategies to counteract their host's apoptotic responses. An alternative anti-apoptotic strategy for viruses is to adopt a cryptic (asymptomatic) infection such that the productive virus infection is undetectable by the host's immune surveillance, whereby only a subset of few viral genes is expressed. Perhaps this partially explains the asymptomatic infection state of GpSGHV, as well as the delayed development of SGH (i.e. SGH symptoms only develop in the $F_{1}$ progenies produced by GpSGHV-injected mothers) [23]. Another strategy for a virus may be to adopt an immediate and rapid multiplication and assembly strategy soon after infection such that large amounts of its progeny virions are produced before the host mounts an effective apoptotic response. If the virus adopts this strategy, any apoptotic response from the host after virion assembly might enable dissemination of the virus within the host [108]. Significantly, in addition to possessing the iap gene, it is known 


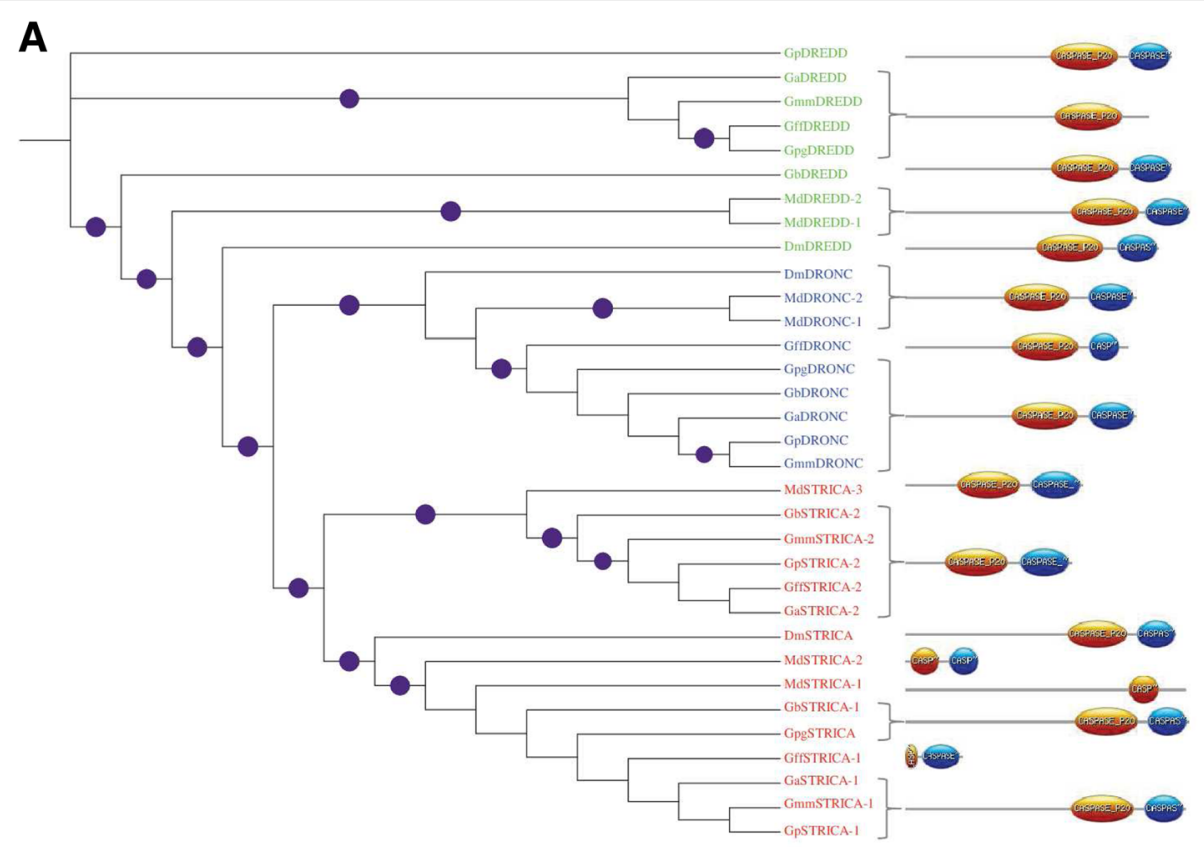

B

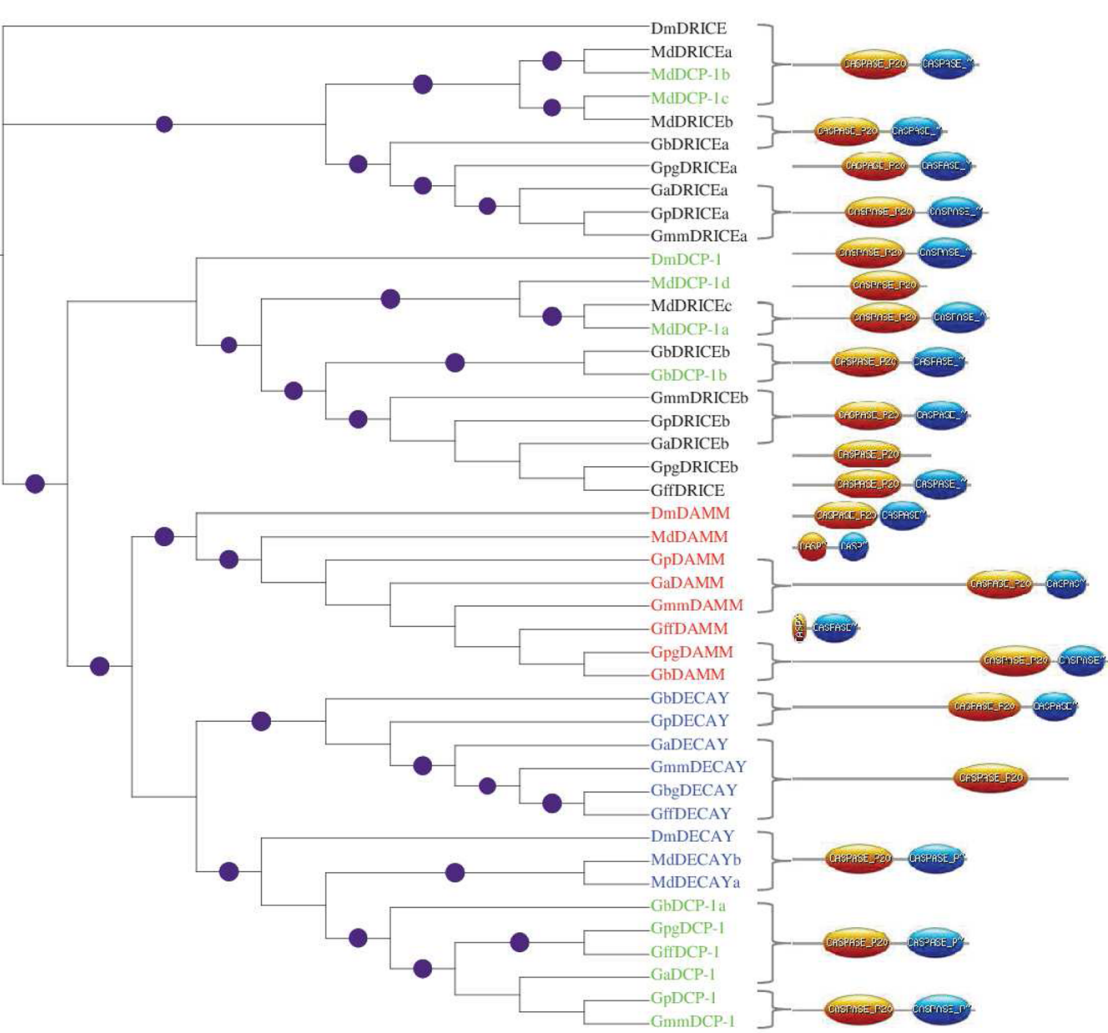

Fig. 1 Phylogenetic analysis of initiator caspases (DRONC, DREDD and STRICA), and effector caspases (DAMM, DrICE, DECAY and DCP-1): a The three initiator caspases showed clear clustering across Drosophila, housefly and the Glossina species. b The effector caspase DAMM, and to a large extend DECAY, segregated clearly, but not for DRICE and DCP-1. Shown are the caspase prodomains of variable lengths, followed by p20 (orange) and p10 (blue) units that contain essential amino acid residues required for substrate recognition and catalysis. The prodomains were excluded during the phylogenetic reconstructions. Purple circles indicate bootstrap support of $>80 \%$ 


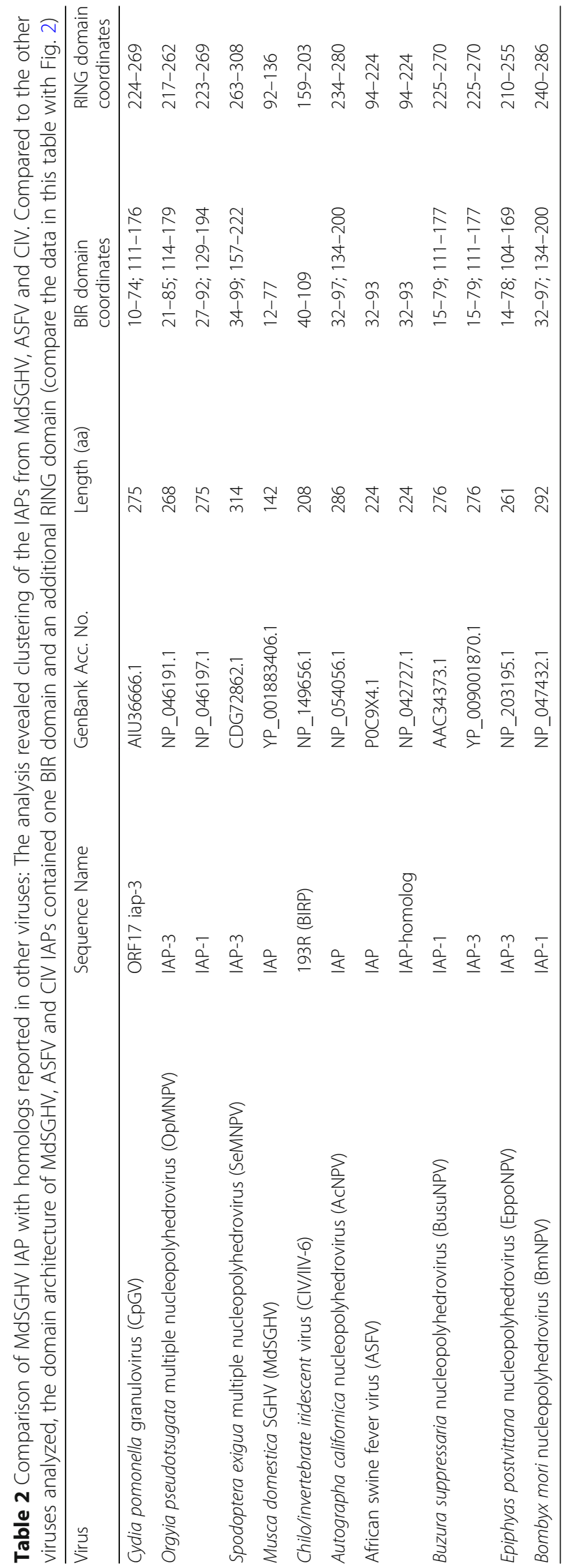



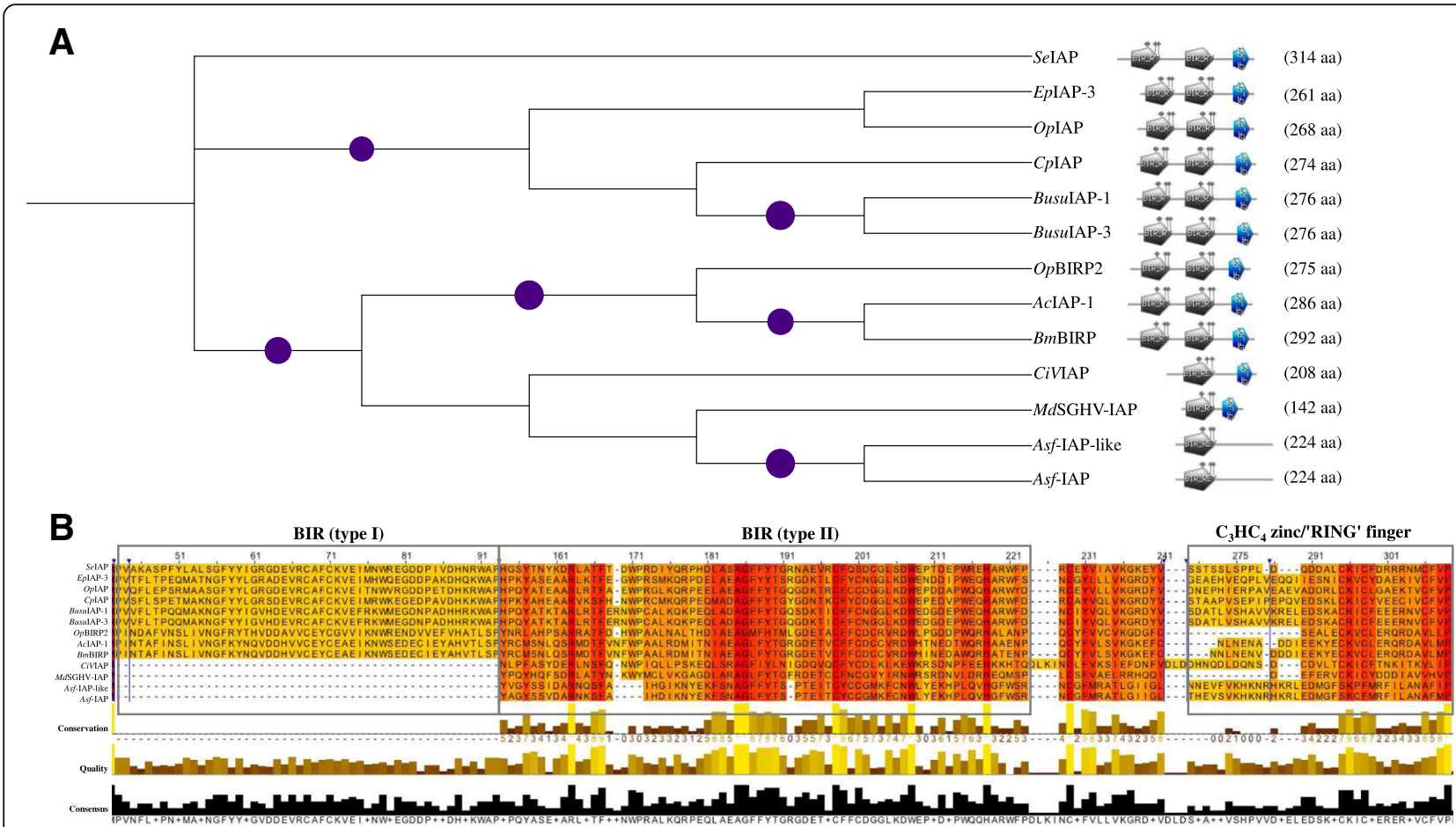

Fig. 2 Phylogenetic analyses of IAP homologs from several viruses: a Phylogenetic clustering of MdSGHV IAP with homologs from Spodoptera exigua MNPV (selAP), Epiphyas postvittana MNPV (EpIAP), Orgia pseudotsugata NPV (OpIAP/BIRP2, Cydia pomonella granulovirus (CpIAP), Buzura suppressaria NPV (BusulAP-1/3), Autographa californica MNPV (AcIAP), Bombyx mori NPV (BmBIRP), Chilo iridescent virus (CiVIAP), and African swine fever virus (Asf-IAP/IAP-like). b Alignment of the IAP showing the functional baculovirus IAP repeat domains (BIR-1/2), and zinc binding fold. The IAPs from MdSGHV, AsfV and CIV contained a single BIR domain. Note that the irregular pentagons in Panel (a) represent types I and II BIR (in grey color), and the $\mathrm{C}_{3} \mathrm{HC}_{4}$ zinc/'RING' (Really Interesting New Gene) finger domain (in blue color), These regions are marked in Panel (b) of the figure (rectangular boxes)

that unlike GpSGHV, MdSGHV rapidly multiplies and induces detectable SGH symptoms in $100 \%$ of injected flies within 2-3 days post injection [3]. This rapid replication and possession of iap gene by MdSGHV may provide this virus with an additional layer of protecting itself from the housefly's apoptotic response as compared to GpSGHV.

\section{Evolution of SGHVs and the host immune genes Immune-related genes in the SGHVs}

As stated elsewhere in this review, the two SGHVs whose genomes have been fully sequenced have significant differences in their genome sizes and the number of genes, i.e. $190 \mathrm{~kb} / 160-174$ genes and $\sim 124 \mathrm{~kb} / 108$ genes in GpSGHV and MdSGHV, respectively. These differences raise the question of the evolutionary origins of the 'novel' genes in the GpSGHV-Eth genome in comparison to the genomes of the GpSGHV-Uga isolate and MdSGHV. To be noted is the fact that 37 MdSGHV genes are homologous to 42 genes in the GpSGHV-Uga genome (five MdSGHV genes are homologs to gene pairs in GpSGHV-Uga) [13]. Compared to the GpSGHV-Uga isolate, the GpSGHV-Eth isolate has added into its genome 24 putative 'novel' genes, but appears to have lost 11 genes and has 13 non-canonical genes (i.e. they have either CTG or TTG start codons instead of ATG) [6]. It is unclear whether the 'novel' ORFs in GpSGHV-Eth were due to criteria used to assign ORFs to the two GpSGHV isolates. However, four of the 24 'novel' genes in GpSGHV-Eth harbor notable functional motifs. For instance the repetitive interspersed family (Rif/Stevor), viral small hydrophobic protein (v-SHP), and repeat-associated mysterious proteins (RAMPs) domains, which are important for gene duplication, virus docking and viral genome cleavage, respectively [6]. Moreover, another four of the 'novel' genes are both transcribed and translated, implying that they could be functional in GpSGHV-Eth [6]. Together, one could infer that these genes were co-evolutionarily acquired, followed by either their loss, and/or duplication of the essential domains to perform specific functions.

Nine of the MdSGHV/GpSGHV shared genes are homologs to the so-called core genes in baculoviruses [132], while 13 genes are unique to both SGHVs, but without homology to any known viral or cellular genes [13]. These shared SGHV genes can be considered as the ancient 'core' genes that have been vertically inherited from the ancestral or original member of the Hytrosaviridae family, and subsequently conserved amongst the 
descendants in this family. The remaining repertoire of 'non-core' genes, most of which encode proteins of unknown functions (PUFs) are presumably genus-specific (Muscavirus vs. Glossinavirus), or lineage-specific (GpSGHV-Eth vs. GpSGHV-Uga). The genus-specific genes may have been originally captured from the genomes of ancestral host species, followed by numerous duplication events. Similarly, the lineage-specific genes may have originated from unilateral gene transfers from unrelated viral (haplotype/isolate) genomes, followed by intra-genomic domain duplication and fusion events. Compared with the genome of the MdSGHV, the genomes of the two GPSGHV isolates harbor more 'core' genes found in the genomes of baculoviruses, nudiviruses, and entomopoxviruses (EPV) [132, 133]. These genes play critical roles in transcription of viral genes, viral packaging, assembly and egress. The core genes in the GpSGHV isolates that are not found in MdSGHV include Desmoplakin/Ac66 and core protein P4a (Melanoplus sanguinipes EPV), RNA polymerase transcription factor (Amscata moorei EPV), and the early/late gene expression factor-5 (LEF-5; Culex nigripalpus NPV) and LEF-8 (Panaeus monodon nudivirus; PmNV) [4, 6, 132]. Moreover, compared with the GpSGHV-Uga isolate, the genome of the more virulent GpSGHV-Eth isolate has distinct clusters of genes with deletions and insertions [6]. Together, these genomic differences between the SGHVs are pointing to a more complicated evolutionary history in the case of GpSGHV isolates compared to the MdSGHV.
Interestingly, unlike the core viral genes, most of the 'acquired' genes are not essential for virus replication, rather, these genes ensure a conducive cellular environment for virus replication [134, 135], for instance by mediating avoidance of the host's immune system and prevention of inflammatory responses. Amongst these, genes encoding proteins that are homologs to host/cellular immunity-related proteins are particularly interesting because they are likely to have been acquired to mimic or interfere with the immune functions of their cellular homologs. This phenomenon is unique to DNA viruses because the RNA viruses utilize their high mutation rates to escape the host immune responses and persist in their hosts [97]. Examples are the virally-encoded interleukin-10 homologs by several DNA viruses, such as the homolog that potently suppress host immune responses against HCV [136], and the baculovirusencoded IAP [137]. Notably, the homologies between the viral and cellular proteins may either be throughout the entire amino acid sequences, or only in conserved (functional) domains. Regardless of homology levels, these virally-encoded proteins outmaneuver their hostencoded homologs in modulating inflammatory and immune functions such that the virus is not eliminated and the host cell, in which case persistent infection state would prevail.

Table 3 details 14 of the GpSGHV-encoded proteins that are homologous to known cellular genes, of which only two have limited homologies ( 20\%) in MdSGHV, i.e. lecithine cholesterol acytransferase and glutathione

Table 3 SGHV-encoded orthologs of cellular genes: The protein families shown in this table were restricted to those that showed significant domain structural conservations. The proteins listed here have been described during the reporting of the genome sequences of the SGHVs [4-6]

\begin{tabular}{|c|c|c|c|c|c|}
\hline \multirow[t]{2}{*}{ Protein Name } & \multicolumn{2}{|c|}{ GpSGHV ORF (ORF No.) } & \multirow{2}{*}{$\begin{array}{l}\text { Location in } \\
\text { virus particle }\end{array}$} & \multirow{2}{*}{$\begin{array}{l}\text { MdSGHV } \\
\text { (ORF No.) }\end{array}$} & \multirow[t]{2}{*}{ Homology or description } \\
\hline & GpSGHV-Eth & $\overline{\text { GpSGHV-Uga }}$ & & & \\
\hline Lecithine-cholesterol acyltransferase $^{(T, P)}$ & 5 & 5 & $\operatorname{ICSVP}^{ \pm}$ & 46 & Pseudomonas sp. \\
\hline D-3-phosphoglycerate dehydrogenase ${ }^{(T, P)}$ & 6 & 7 & Tegument & - & Clostridium ultunense \\
\hline MAL7P1.132 (T, P) & 8 & 9 & ICSVP & - & Plasmodium falciparum Str. 3D7 \\
\hline UDP-glucose-6 dehydrogenase ${ }^{(T)}$ & 13 & 16 & Unknown & - & Pseudobutyrivibrio ruminis \\
\hline NADH ubiquinone oxidoreductase ${ }^{(T)}$ & 30 & 29 & Virion protein & - & Styphylococcal AgrD protein \\
\hline Maltodextrin glycosyltransferase ${ }^{(T, P)}$ & 39 & 38 & Tegument & - & RGD-domain containing protein \\
\hline Glutathione S-transferase ${ }^{(T, P)}$ & 48 & 46 & Tegument & 84 & Pre-mRNA splicing factor \\
\hline Cellular protein $\mathrm{CBG} 22662^{(\mathrm{T}, \mathrm{P})}$ & 49 & 47 & Tegument & - & Coenorhabditis briggsae \\
\hline Rhoptry protein kinase ${ }^{(T)}$ & 58 & 57 & - & - & Plasmodium yolei Str. 17XNL \\
\hline Signaling mucin HKR1 & 64 & - & - & - & Xenopus (Silurana) tropicalis \\
\hline RpoD protein ${ }^{(\top)}$ & 66 & 59 & - & - & Plasmodium falciparum \\
\hline ECF transporter ${ }^{(T, P)}$ & 75 & 68 & Envelop & - & - \\
\hline Cellular protein PY00593 ${ }^{(T, P)}$ & 124 & 113 & Nucleocapsid & $\mathrm{NaN}$ & Plasmodium yolei Str. 17XNL \\
\hline Tail length tape-measure $(\mathrm{T}, \mathrm{P})$ & 149 & 134 & ICSVP & - & Oenococcus phage phi9805 \\
\hline
\end{tabular}

Expression confirmed by transcriptomics $\left({ }^{\top}\right)$ and proteomics only $\left({ }^{P}\right)$. Unmarked genes have no detectable transcripts or peptides; ${ }^{\mp}$ These proteins do not have specific localization and were designated as 'infected cell-specific viral proteins (ICSVP)' [6] 
S-transferase [4-6]. Nine of the 14 genes have been confirmed to be both transcribed (by RNASeq) and translated (mass spectrometry), implying that they are likely functional in GpSGHV infections [6]. Viruses can be viewed as an assembly of genes (i.e. their genomes are bits of different genes assembled together to form the genetic composition) [138], a phenomenon that partially accounts for the wide range of hosts from which the cellular genes originated (bacterial, parasites, nematodes, vertebrates and bacteriophages) (see Table 3). This is not unusual; some of the well characterized viral genes such as the DNA polymerases and helicases are of phage origin [139]. Nevertheless, the direction of horizontal gene transfers between viral and ancestral cellular genomes and/or vice versa is enigmatic. Whether the cell-derived genes mentioned in Table 3 have any roles in the evolution of GpSGHV is yet to be elucidated.

\section{Immune genes in the housefly and tsetse fly}

Virus evolution pressures their respective hosts to evolve immune counter-measures. Insect immunity consists of three main pillars. One pillar is the humoral immune response composed of the interconnected and synergistic Toll (immunity and developmental functions) and immune deficiency (IMD) pathways [140]. The second pillar consists of cellular responses (e.g. phagocytosis, PPO cascades) that result in pathogen phagocytosis and melanization [141], while as discussed above, the third pillar consists of the RNAi and other multipurpose pathways (e.g. JNK and the JAK/STAT).

The immune genes under these pillars can be broadly grouped in six functional categories, i.e. recognition, signaling, effectors, modulators, melanization, and RNAi (Table 4). The immune genes repertoires in D. melanogaster, An. gambiae, G. pallidipes and M. domestica show species-specific and extensive expansion of the recognition genes. For example, in $M$. domestica, calcium-dependent lectins (CTLs; $n=37$ ) and thioestercontaining proteins (TEPs; $n=22$ ) have expanded when compared to Drosophila (34 CTLs; 10 TEPs), G. pallidipes (17 CTLs; 7 TEPs) and An. gambiae (25 CTLs; 13 TEPs) (see Table 4). The expansion of CTLs and TEPs in $M$. domestica implicates gene duplication driven by selective evolutionary pressures. The TEPs can be characterized as structurally unrelated opsonins that are critical for phagocytosis in many species, from insects to mammals [142]. The significant expansion of TEPs in $M$. domestica is probably an evolutionary necessity to enable this insect to deal with the plethora of diets/habitat-associated microbes. Compared to the other three insects, $M$. domestica seems to have acquired two additional homologs of the Down-syndrome adhesion molecule-1 (Dscam1), an insect opsonin equipped to cope with a broad range of pathogens [143].

The core immune signaling genes (Toll, Imd, JAK/ STAT and JNK pathways) showed single-copy orthologs with similar divergence levels across the four dipterans (D. melanogaster, An. gambiae, M. domestica and G. pallidipes; see Table 4). Notably, although these pathways are traditionally thought to protect insects against infections by bacteria, fungi and parasites, evidence suggest that these pathways play a significant role in the defense against many viruses in both mosquitoes and Drosophila [83, 144]. Despite the overall conservation of the signaling immune genes in the four insects analyzed here, there are a few cases of gene losses and gains. For example, compared to the four Spätzle and one Dorsal protein homologs in M. domestica, G. pallidipes has expanded these two genes to seven spätzle and eight dorsal genes. Spätzle is an insect hemolymph cytokine, which in the moth, Manduca sexta, functions as a ligand that stimulates a broad-spectrum immune response to kill invading pathogens [145]. In Drosophila, Spätzle initiates a signaling cascade that culminates in the release of Dorsal from the protein Cactus to activate genes that are important for dorsal-ventral patterning in early embryonic development [145].

The effector and modulator gene categories seemed significantly diverged across the species, with the exception of single copies of nitric oxide synthase (NOS) in each species. There seems to be species-specific and extensive expansion of the modulator genes, with large expansion of the CLIP-domain serine proteases (CLIPs) and serpins in $M$. domestica compared to G. pallidipes (Table 4). In insect hemolymph, CLIPs proteolytically activate Spätzle (discussed in the previous paragraph) and other proteins [146], thereby serving as a potent mediator of insect immunity against invading pathogens. Most likely, the lifestyle, nutrition and ecology of the housefly have evolutionarily driven the selection of a large arsenal of effector and modulator genes to counter potential pathogens. In terms of the humoral responses, the expansion in the housefly of the prophenoloxidase (PPO) gene family $(n=25)$ is notable, especially compared to the significantly lower numbers of PPOs in Drosophila $(n=3)$, An. gambiae $(n=9)$, and G. pallidipes $(n=8)$ (see Table 4). In many arthropods, the PPO cascade is not only evolutionary conserved, but it is the primary extracellular pathway tasked with wound healing and melanization of infecting pathogens [147], which may be important for the ecology of the housefly. Further, the by-products of the PPO pathway have been reported to have antiviral effects in some viruses such as the baculoviruses [148-150], SINV [151], and Semliki Forest virus (SFV) [152]. The enrichment of the PPO pathway in $M$. domestica warrants further investigations 
Table 4 Major immunity genes in M. domestica and G. pallidipes: The immune genes described for the model insect, Drosophila melanogaster and the African malaria mosquito, Anopheles gambiae were obtained from the ImmunoDB [161]. The pathway for the putative immune-related proteins in G. pallidipes and M. domestica were verified by BLASTp searches at the Insect Innate Immunity Database (IIID) $\left(\leq 10^{-6}\right.$; bit score > 75) [164]. The pathways shown in this table have been reviewed by Kingsolver et al. [174]

\begin{tabular}{|c|c|c|c|c|c|c|}
\hline \multicolumn{4}{|c|}{ Description of the functions and pathways of immune-related proteins in Drosophila melanogaster } & \multicolumn{3}{|c|}{ Numbers of homologs } \\
\hline Immune function & Key pathway & Protein name/sub-family & D. melanogaster & An. gambiae & M. domestica & G. pallidipes \\
\hline \multirow[t]{4}{*}{ Pathogen recognition } & Lectin & Calcium-dependent (C-type) lectins (CTLs) & 34 & 25 & 37 & 17 \\
\hline & \multirow[t]{3}{*}{ Phagocytic } & $\begin{array}{l}\text { Down Syndrome cell adhesion molecule-1 } \\
\text { (Dscam1) }\end{array}$ & 1 & 1 & 3 & 1 \\
\hline & & $\begin{array}{l}\text { Pathogen pattern-recognition receptor } \\
\text { Eater (Eater) }\end{array}$ & 1 & 1 & - & 1 \\
\hline & & Thioester-containing proteins (TEPs) & 10 & 13 & 22 & 7 \\
\hline \multirow[t]{8}{*}{ Signaling } & \multirow[t]{8}{*}{ Toll } & Spätzle-like proteins (Spätzle) & 6 & 6 & 4 & 7 \\
\hline & & Toll receptors (Tolls) & 9 & 10 & 7 & 6 \\
\hline & & MyD88 & 1 & 1 & 1 & 1 \\
\hline & & Tube & 1 & 1 & 1 & 1 \\
\hline & & Pelle & 1 & 1 & 1 & 1 \\
\hline & & TNF-receptor-associated factor-like (TRAF) & 1 & 1 & 1 & 2 \\
\hline & & Cactus & 1 & 1 & 1 & 2 \\
\hline & & Dorsal & 2 & - & 1 & 8 \\
\hline \multirow[t]{9}{*}{ Signaling } & \multirow[t]{9}{*}{ Imd } & Immune deficiency (Imd) & 1 & 1 & 1 & - \\
\hline & & TGF-beta activated kinase 1 (Tak1) & 1 & 1 & 1 & 1 \\
\hline & & Kenny & 1 & 1 & - & 1 \\
\hline & & $\begin{array}{l}\text { Inhibitor of nuclear factor kB kinase } \beta \\
\text { (IKKb/ird5) }\end{array}$ & 1 & 1 & 1 & 1 \\
\hline & & Fas-associated death domain (FADD) & 1 & 1 & 1 & 1 \\
\hline & & Poor Imd response upon knock-in (PIRK) & 1 & - & 1 & - \\
\hline & & Caspar (Casp) & 1 & 1 & 1 & 1 \\
\hline & & TAK1-associated binding protein 2 (Tab2) & 1 & 1 & 1 & 1 \\
\hline & & Relish (Rel) & 1 & 2 & 1 & 2 \\
\hline \multirow[t]{3}{*}{ Signaling } & \multirow[t]{3}{*}{ JAK/STAT } & Domeless & 1 & 1 & - & 1 \\
\hline & & Janus kinase (Hopscotch) & 1 & 1 & 1 & 1 \\
\hline & & $\begin{array}{l}\text { Signal transducer and activator of } \\
\text { transcription (Stat92E) }\end{array}$ & 1 & 2 & 1 & 2 \\
\hline \multirow[t]{3}{*}{ Signaling } & \multirow[t]{3}{*}{ JNK } & Jun kinase (JNK)/basket & 1 & 1 & 1 & 1 \\
\hline & & Dual-specificity MAPK hemipterous (hep) & 1 & 1 & 1 & 1 \\
\hline & & Jun-related antigen (Jra/Jun) & 1 & 1 & - & 2 \\
\hline \multirow[t]{3}{*}{ Effectors } & \multirow[t]{3}{*}{ AMP } & Antimicrobial peptides (AMPs) & 21 & 11 & 21 & 4 \\
\hline & & Lysozyme & 17 & 8 & 29 & 5 \\
\hline & & Nitric oxide synthase (NOS) & 1 & 1 & 1 & 1 \\
\hline \multirow[t]{2}{*}{ Modulators } & Exocytic & CLIP-Domain Serine Proteases (CLIPS) & 47 & 55 & 132 & 72 \\
\hline & Proteolytic & Serine protease inhibitors (serpins) & 29 & 21 & 35 & 14 \\
\hline $\begin{array}{l}\text { Melanization or } \\
\text { Encapsulation }\end{array}$ & Humoral & Prophenoloxidase (PPO) & 3 & 9 & 25 & 8 \\
\hline \multirow[t]{5}{*}{ RNAi response } & \multirow{5}{*}{$\begin{array}{l}\text { Small RNA Regulatory } \\
\text { Pathways (SRRPs) }\end{array}$} & Argonaute (Ago) & 3 & 3 & 2 & 3 \\
\hline & & Armitage (Armi) & 1 & 1 & 1 & 1 \\
\hline & & Aubergine (Aub) & 1 & 1 & 1 & 1 \\
\hline & & Dicer (Dcr) & 2 & 2 & 2 & 1 \\
\hline & & Drosha & 1 & 1 & 1 & 1 \\
\hline
\end{tabular}


Table 4 Major immunity genes in M. domestica and G. pallidipes: The immune genes described for the model insect, Drosophila melanogaster and the African malaria mosquito, Anopheles gambiae were obtained from the ImmunoDB [161]. The pathway for the putative immune-related proteins in G. pallidipes and M. domestica were verified by BLASTp searches at the Insect Innate Immunity Database (IIID) $\left(\leq 10^{-6}\right.$; bit score > 75) [164]. The pathways shown in this table have been reviewed by Kingsolver et al. [174] (Continued)

\begin{tabular}{|c|c|c|c|c|c|c|}
\hline \multicolumn{4}{|c|}{ Description of the functions and pathways of immune-related proteins in Drosophila melanogaster } & \multicolumn{3}{|c|}{ Numbers of homologs } \\
\hline Immune function & Key pathway & Protein name/sub-family & D. melanogaster & An. gambiae & M. domestica & G. pallidipes \\
\hline & & Loquacious (Loqs) & 1 & 1 & 2 & 1 \\
\hline & & Partner of Drosha (Pasha) & 1 & 1 & - & 1 \\
\hline & & $\begin{array}{l}\text { P-element induced wimpy } \\
\text { testis (Piwi) }\end{array}$ & 1 & 1 & 1 & 1 \\
\hline & & R2D2 & 1 & 1 & 1 & 2 \\
\hline & & $\begin{array}{l}\text { Spindle-E (Spn-E) or } \\
\text { Homeless }\end{array}$ & 1 & 1 & 2 & 1 \\
\hline & & $\begin{array}{l}\text { Tudor staphylococcal nuclease } \\
\text { (Tudor-SN) }\end{array}$ & 1 & 1 & 1 & 1 \\
\hline
\end{tabular}

of the extent to which the pathway is engaged in the pathogenesis of SGHVs.

The three key RNAi genes, Ago-2, Dcr-2 and R2D2 are arguably amongst the fastest evolving, and in Drosophila, they are subject to immense positive selection and selective sweeps [153, 154]. Compared to Drosophila, An. gambiae and G. pallidipes, $M$. domestica appears to have lost Ago-1 and Pasha, but has acquired extra copies of Loquacious (Loqs) and Spindle-E/Homeless (Spn-E/hls) and expanded Ago-2 (Table 4). On the other hand, G. pallidipes has duplicated R2D2 (Table 4; Fig. 3). In Drosophila, Spn-E (and Piwi and Aubergine) is involved in the RNAi-mediated (via the piRNA branch) silencing of heterochromatin [155]. Specifically, $S p n-E$ is required for activation of RNAi-mediated regulation of maternal mRNAs during oogenesis in Drosophila [156], and in defense against transposable elements [157], but its anti-viral roles are yet to be defined. One of the $M$. domestica Spn-E duplicates contained all the three signature domains found in the Drosophila Spn-E; the Spn-E homologs from mosquito and tsetse lacked the catalytic tetrad DExH box/Tudor domain (see Fig. 3c). However, absence of the catalytic tetrad is not unique because only a subset of the family possesses cleavage activity [158]. The three cofactors of Dcr and Drosha (Pasha, R2D2 and Loqs) that are required in the first step of the RNAi pathway (i.e. generation of RNAs) $[159,160]$ contained the functional domains. Further, of the four AGO proteins (AGO 1-4), AGO-2 is singly capable of executing to the ultimate aim of the RNAi pathway (decimation of target mRNAs); knockdown of Ago-1, -2 and -3 genes does not compromise the integrity of the RNAi pathway [159]. This partially makes the loss of Ago-1 gene in M. domestica inconsequential. Notably, the M. domestica Dcr-2 homolog lacks the dsRNA-binding domain (Fig. 3b), thus raising the question of what effects this has in the functionality of the protein.

The species-specific expansions and/or losses of the RNAi genes may have significant implications on the functionality of the pathway in tsetse and the housefly. Although it is yet to be experimentally validated whether all the RNAi key genes are expressed in the housefly, at least Dcr-2 and Ago-2 are expressed in G. pallidipes. Significantly, it has been proposed that RNAi is involved in the diversification and evolution of some viruses such as WNV and DENV in mosquitoes [144]. Consequently, given the complexity of GpSGHV haplotypes/isolates [6, $25,27]$ compared to MdSGHV, one could surmise that the RNAi pathway might put a potent natural selection pressure on GpSGHV to favor evolution and maintenance of novel viral haplotypes.

\section{Conclusions}

The data presented in this review suggest that the ecologies of the housefly and tsetse fly (i.e. how they interact with their environment or ecosystems either individually or as communities) and their life-history traits have influenced the persistence and transmission strategies, and hence the co-evolution between the host and the particular SGHV. In the case of the GpSGHV, so far, the absence of any known alternative reservoir host(s) may have necessitated the selection for vertical transmission (in a covert form) of the virus to facilitate its maintenance within tsetse fly populations between the SGH epizootics. Moreover, the existence of mixed modes of vertical and horizontal transmission may be evolutionary beneficial to the GpSGHV because it may contribute to the generation and maintenance of the virus diversity (haplotypes). For the MdSGHV, the possibility of existence of muscid hosts 


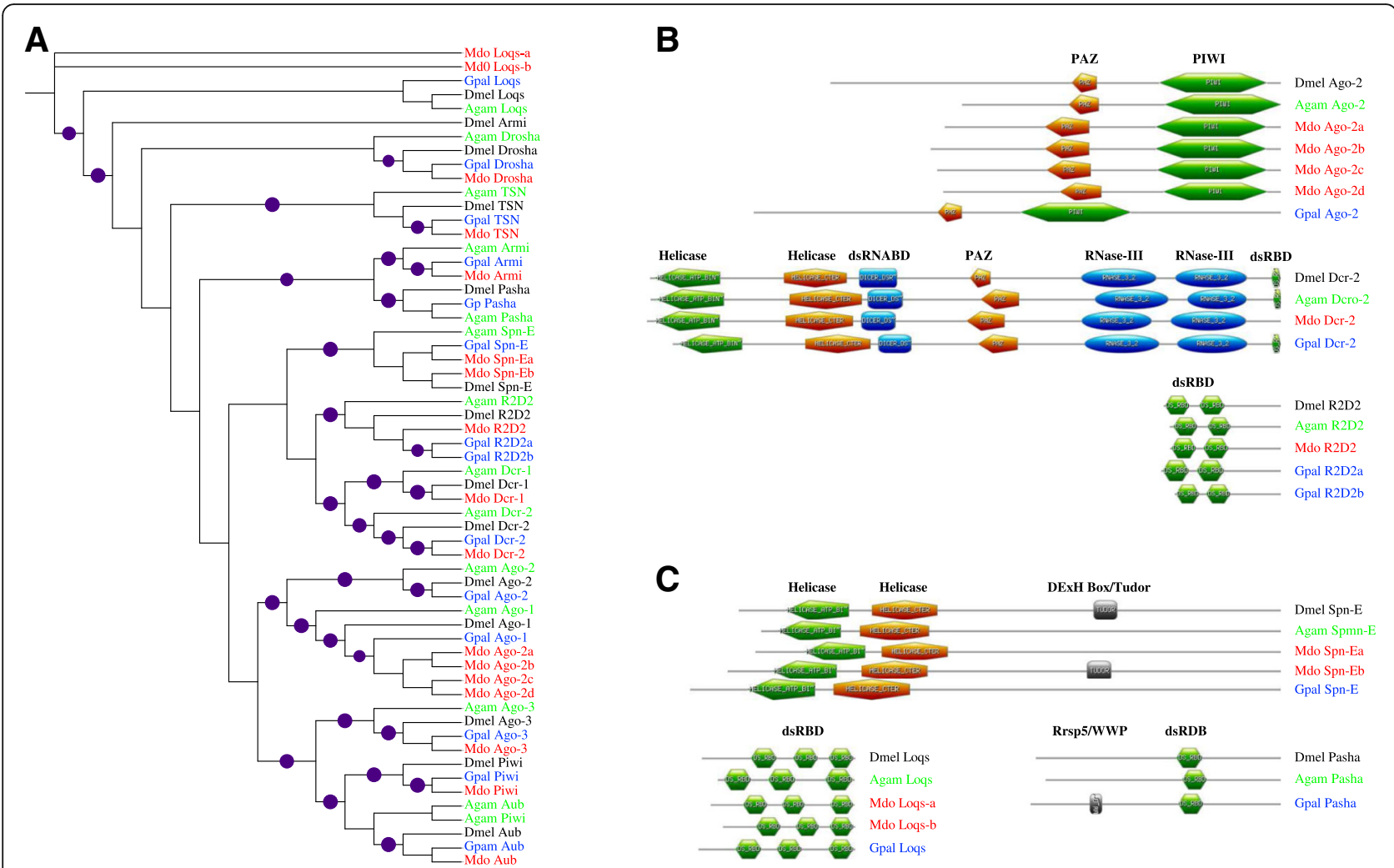

Fig. 3 Phylogenetic analysis of the key RNAi pathway proteins in dipterans: a Clustering of the housefly and tsetse fly RNAi proteins with their homologs in the fruit fly and the malaria mosquito. $\mathbf{b}$ Domains of the three key RNAi pathway proteins, Ago-2, Dcr-2, R2D2, and $\mathbf{c}$ three of their main cofactors Spn-E, Pasha and Loqs. Purple circles indicate bootstrap support of $>80 \%$. The identities of the domains in the different irregular pentagon/hexagon shapes in Panels (b) and (c) in this figure are shown on top of each shape. Abbreviations: -PIWI, P-element Induced W/mpy testis gene domain; PAY, PIWI-Argonaute-Zwille domains; dsRNABD/ dsRBD, double-stranded RNA-binding domain/motif; RNase-III, Ribonuclease III domain; DExH Box/Tudor, EAD/DEAH box helicases family protein domains; Rrsp5/WWP, rice root-specific promoter protein

5/Tryptophan-tryptophan-proline motif

other than the housefly as reservoir or alternative hosts may have influenced selection for horizontal transmission of this virus. Additionally, the combination of horizontal transmission and the highly virulent nature of the MdSGHV (i.e. the virus infects only symptomatically) potentially hints to this virus as a regulating factor for housefly populations in a density-dependent or independent manner. However, further long-term studies are required to investigate the SGHVs infection and transmission dynamics and the roles of these viruses on regulations of the housefly and tsetse fly populations and community dynamics.

Many questions however remain unanswered with regard to SGHVs dynamics, particularly in natural populations of their respective hosts. For instance, why are GpSGHV-induced epizootics (SGH outbreaks) such rare occurrence in the field, and what are the genetic elements accounting for the differences in the pathogenesis of the two GpSGHV isolates? On the other hand, in the case of the MdSGHV for example, how is this virus maintained when the host populations fluctuate to low densities, and does the MdSGHV virulence (solely symptomatic infections) temporally and spatially modulate the community structures of the houseflies in nature? A further and even more challenging question is as to what extent the tripartite host-SGHV-microbiota interactions influences SGH epizootics. Finally, SGHVs are attractive 'explorers' to dissect the defense responses of their hosts and to study the transmission modes of large DNA viruses in dipteran flies.

\section{Methods}

Genome-wide identification of G. pallidipes and $M$. domestica immune genes

Annotated immune genes of D. melanogaster and An. gambiae sensu stricto were retrieved from ImmunoDB [161] and used to query (BLASTp; $e$-value $\leq 10^{-4}$ ) the predicted proteomes of G. pallidipes Austen, and $M$. domestica Linnaeus (retrieved from VectorBase [162]). Canonical domains in the identified immune genes were ascertained using Pfam [163], and pathways confirmed 
by BLASTp searches in the Insect innate Immunity Database (IIID) [164].

\section{Phylogenetic analysis}

To decipher phylogenetic relatedness of orthologous and paralogous immune genes in the genomes of $A$. gambiae, $D$. melanogaster, G. pallidipes and $M$. domestica, the retrieved sequences were aligned using MAFFT v7 [165], manually curated in Jalview v2.9 [166], and used for phylogenetic reconstructions using PhyML 3.0 [167] and MrBayes v3.2 [168]. The robustness of internal branches was evaluated using 100 bootstraps. The trees were rendered using iTOL v3.5.3 [169].

\begin{abstract}
Abbreviations
AcNPV: Autographa californica nucleopolyhedrovirus; Ago: Argonaute; AMP: Antimicrobial peptides; ASFV: African swine fever virus; BmNPV: Bombyx mori nucleopolyhedrovirus; BusuNPV: Buzura suppressaria nucleopolyhedrovirus; CA/CC: Corpora-allata/cardiaca glands; Caspase: Cysteine-dependent aspartate-specific protease; CIV/IIV-6: Chilo/ invertebrate iridescent virus; CLIP: CLIP-domain Serine Protease; CpGV: Cydia pomonella granulovirus; CrPV: Cricket paralysis virus; CTL: C-type lectin; DAMM: Death associated molecule related to Mch2; DCP-1: Death caspase protein 1; Dcr: Dicer; DCV: Drosophila C virus; DECAY: Death executioner caspase-related to Apopain/Yama; DENV: Dengue virus; DIAP1: Drosophila inhibitor of apoptosis protein 1; Dnr1: Defense repressor-1;

DREAM: Downstream regulatory element-antagonist modulator; DREDD: Death-related ced-3/Nedd2; DrICE: Drosophila interleukin-1 $\beta$ converting enzyme; DRONC: Death regulator Nedd2-like caspase; Dscam1: Down Syndrome cell adhesion molecule-1; Eater: Pathogen patternrecognition receptor Eater; EBV: Epstein-Barr virus; EppoNPV: Epiphyas postvittana nucleopolyhedrovirus; EPV: Entomopoxvirus; FHV: Flock house virus; GpSGHV: Glossina pallidipes salivary gland hypertrophy virus; HCV: Human cytomegalovirus; HRF-1: Host range factor-1; HSV-1: Herpes simplex virus 1; HVS: Herpesvirus saimiri; IAP: Inhibitor of apoptosis; IIID: Insect innate immunity database; Imd: Immune deficiency; KSV: Kaposi's sarcoma-associated herpesvirus; LEF: Early/late gene expression factor; Loqs: Loquacious; MdSGHV: Musca domestica salivary gland hypertrophy virus; miRNA: MicroRNA; NOS: Nitric oxide synthase; OpMNPV: Orgyia pseudotsugata multiple nucleopolyhedrovirus; PPO: Prophenoloxidase; PUF: Protein of unknown function; RAMPs: Repeat-associated mysterious proteins; REL1: Relish protein; Rif/Stevor: Repetitive interspersed family; RNAi: RNA interference; ROS: Reactive oxygen species; RT-qPCR: Reverse transcriptase quantitative PCR; SeMNPV: Spodoptera exigua multiple nucleopolyhedrovirus; Serpin: Serine protease inhibitors; SFV: Semliki Forest virus; SINV: Sindbis virus; siRNA: short interfering RNA; SpexNPV: Spodoptera exempta nucleopolyhedrovirus; Spn-E/hls: Spindle-E/Homeless; Spz1A: Spätzle 1A; STRICA: Serine/Threonine-rich caspase-A; TEP: Thioester-containing protein; v-SHP: viral small hydrophobic protein; WNV: West Nile virus
\end{abstract}

\section{Acknowledgements}

IKM is a recipient of a sandwich PhD grant from Wageningen University.

\section{Funding}

The publication cost of this article was funded by the Joint FAO/IAEA Division of Nuclear Techniques in Food and Agriculture, Vienna, Austria (Coordinated Research Project No. D42015).

\section{About this supplement}

This article has been published as part of BMC Microbiology Volume 18 Supplement 1, 2018: Enhancing Vector Refractoriness to Trypanosome Infection. The full contents of the supplement are available online at https:// bmcmicrobiol.biomedcentral.com/articles/supplements/volume-18supplement-1.

\section{Authors' contributions}

HMK and DBG conceived, designed and coordinated the study, and drafted the manuscript. EKM, IKM, and HMK participated in data acquisition, bioinformatics analyses and data interpretations. GD-U, MJBV and AMMA contributed in writing the manuscript. MMVO and JMV critically revised the manuscript for intellectual context. All the authors read and approved the final version of the manuscript.

\section{Ethics approval and consent to participate}

Not applicable

\section{Consent for publication}

Not applicable

\section{Competing interests}

The authors declare that they have no competing interests.

\section{Publisher's Note}

Springer Nature remains neutral with regard to jurisdictional claims in published maps and institutional affiliations.

\section{Author details}

${ }^{1}$ Biotechnology Research Institute, Kenya Agricultural and Livestock Research Organization, P.O Box 57811, Kaptagat Rd, Loresho, Nairobi 00200, Kenya. ${ }^{2}$ Insect Pest Control Laboratory, Joint FAO/IAEA Division of Nuclear Techniques in Food and Agriculture, Wagrammer Straße 5, A-1400 Vienna, Austria. ${ }^{3}$ Entomology and Nematology Department, University of Florida, 970 Natural Area Drive, Gainesville, FL 32611, USA. ${ }^{4}$ Department of Biochemistry and Molecular Biology, Egerton University, P.O. Box 536, Njoro 20115, Kenya. ${ }^{5}$ Laboratory of Virology, Wageningen University and Research, 6708 PB Wageningen, The Netherlands. ${ }^{6}$ Present Address: US National Poultry Research Centre, Southeast Poultry Research Laboratory, USDA-ARS, 934 College Station Road, Athens, GA 30605, USA.

Published: 23 November 2018

\section{References}

1. Abd-Alla AM, Vlak JM, Bergoin M, Maruniak JE, Parker AG, Burand JP, et al. Hytrosaviridae: a proposal for classification and nomenclature of a new insect virus family. Arch Virol. 2009;154:909-18.

2. Kariithi HM, van Oers MM, Vlak JM, Vreysen MJ, Parker AG, Abd-Alla AM. Virology, epidemiology and pathology of Glossina hytrosavirus, and its control prospects in laboratory colonies of the tsetse fly, Glossina pallidipes (Diptera; Glossinidae). Insects. 2013;4:287-319.

3. Kariithi HM, Meki IK, Boucias DG, Abd-Alla AM. Hytrosaviruses: current status and perspective. Curr Opin Insect Sci. 2017;22:71-8.

4. Garcia-Maruniak A, Maruniak JE, Farmerie W, Boucias DG. Sequence analysis of a non-classified, non-occluded DNA virus that causes salivary gland hypertrophy of Musca domestica, MdSGHV. Virology. 2008;377:184-96.

5. Abd-Alla AMM, Cousserans F, Parker AG, Jehle JA, Parker NJ, Vlak JM, et al. Genome analysis of a Glossina pallidipes salivary gland hypertrophy virus reveals a novel, large, double-stranded circular DNA virus. J Virol. 2008;82: 4595-611.

6. Abd-Alla AM, Kariithi HM, Cousserans F, Parker NJ, Ince IA, Scully ED, et al. Comprehensive annotation of Glossina pallidipes salivary gland hypertrophy virus from Ethiopian tsetse flies: a proteogenomics approach. J Gen Virol. 2016;97:1010-31.

7. Jehle JA, Abd-Alla AM, Wang Y. Phylogeny and evolution of Hytrosaviridae. J Invertebr Pathol. 2013;112:S62-7.

8. Wang $Y$, Jehle JA. Nudiviruses and other large, double-stranded circular DNA viruses of invertebrates: new insights on an old topic. J Invertebr Pathol. 2009;101:187-93.

9. Ishimwe E, Hodgson JJ, Clem RJ, Passarelli AL. Reaching the melting point: degradative enzymes and protease inhibitors involved in baculovirus infection and dissemination. Virology. 2015;479-480:637-49.

10. Lietze V-U, Abd-Alla A, Vreysen M, Geden CC, Boucias DG. Salivary gland hypertrophy viruses: a novel group of insect pathogenic viruses. Annu Rev Entomol. 2011;56:63-80.

11. Abd-Alla AMM, Parker AG, Vreysen MJB, Bergoin M. Tsetse salivary gland hypertrophy virus: hope or hindrance for tsetse control? PLoS Negl Trop Dis. 2011;5:e1220. 
12. Arif $B$, Pavlik L. Insect cell culture: virus replication and applications in biotechnology. J Invertebr Pathol. 2013;112:S138-41.

13. Garcia-Maruniak A, Abd-Alla AMM, Salem TZ, Parker AG, van Oers MM, Maruniak JE, et al. Two viruses that cause salivary gland hypertrophy in Glossina pallidipes and Musca domestica are related and form a distinct phylogenetic clade. J Gen Virol. 2009;90:334-46.

14. Lietze V-U, Geden CJ, Doyle MA, Boucias DG. Disease dynamics and persistence of Musca domestica salivary gland hypertrophy virus infections in laboratory house fly (Musca domestica) populations. Appl Environ Microbiol. 2012;78:311-7.

15. Lietze VU, Geden CJ, Blackburn P, Boucias DG. Effects of salivary gland hypertrophy virus on the reproductive behavior of the housefly, Musca domestica. Appl Environ Microbiol. 2007;73:6811-8.

16. Kariithi HM, Yao X, Yu F, Teal PE, Verhoeven CP, Boucias DG. Responses of the housefly, Musca domestica, to the hytrosavirus replication: impacts on host's vitellogenesis and immunity. Front Microbiol. 2017:8:583.

17. Prompiboon P, Lietze V-U, Denton JSS, Geden CJ, Steenberg T, Boucias DG. Musca domestica salivary gland hypertrophy virus, a globally distributed insect virus that infects and sterilizes female houseflies. Appl Environ Microbiol. 2010;76:994-8

18. Nayduch D. Flourishing in filth: house fly-microbe interactions across life history. Ann Entomol Soc Am. 2017;110:6-18.

19. Geden CJ, Lietze V-U, Boucias DG. Seasonal prevalence and transmission of salivary gland hypertrophy virus of house flies (Diptera: Muscidae). J Med Entomol. 2008:45:42-51.

20. Lietze V-U, Keesling JE, Lee JA, Vallejo CR, Geden CJ, Boucias DG. Muscavirus (MdSGHV) disease dynamics in house fly populations - how is this virus transmitted and has it potential as a biological control agent? J Invertebr Pathol. 2013;112:S40-3

21. Antonovics J, Wilson AJ, Forbes MR, Hauffe HC, Kallio ER, Leggett $\mathrm{HC}$, et al. The evolution of transmission mode. Philos Trans R Soc B Biol Sci. 2017;372: 20160083.

22. Abd-Alla AMM, Kariithi HM, Parker AG, Robinson AS, Kiflom M, Bergoin M, et al. Dynamics of the salivary gland hypertrophy virus in laboratory colonies of Glossina pallidipes (Diptera: Glossinidae). Virus Res. 2010;150:103-10.

23. Boucias DG, Kariithi HM, Bourtzis K, Schneider DI, Kelley K, Miller WJ, et al. Trans-generational transmission of the Glossina pallidipes hytrosavirus depends on the presence of a functional symbiome. PLoS ONE. 2013;8:e61150.

24. Leak SGA. Tsetse biology and ecology: their role in the epidemiology and control of trypanosomosis. 1st ed. Wallingford: CAB International, in association with the International Livestock Research Institute, Nairobi, Kenya; 1998.

25. Kariithi HM, Ahmadi M, Parker AG, Franz G, Ros VID, Haq I, et al. Prevalence and genetic variation of salivary gland hypertrophy virus in wild populations of the tsetse fly Glossina pallidipes from southern and eastern Africa. J Invertebr Pathol. 2013;112:S123-32.

26. Goic B, Saleh M-C. Living with the enemy: viral persistent infections from a friendly viewpoint. Curr Opin Microbiol. 2012;15:531-7.

27. Meki IK, Kariithi HM, Ahmadi M, Parker AG, Vreysen MJB, Vlak JM, et al. Hytrosavirus genetic diversity and eco-regional spread in Glossina species. BMC Microbiol. 2018. (In Press).

28. International Glossina Genome Initiative, Attardo GM, Abila PP, Auma JE, Baumann AA, Benoit JB, et al. Genome sequence of the tsetse fly (Glossina morsitans): vector of African trypanosomiasis. Science. 2014;344:380-6.

29. Scott JG, Warren WC, Beukeboom LW, Bopp D, Clark AG, Giers SD, et al. Genome of the house fly, Musca domestica L., a global vector of diseases with adaptations to a septic environment. Genome Biol. 2014;15:466.

30. Lietze V-U, Salem TZ, Prompiboon P, Boucias DG. Tissue tropism of the Musca domestica salivary gland hypertrophy virus. Virus Res. 2011;155:20-7.

31. Lietze V-U, Sims KR, Salem TZ, Geden CJ, Boucias DG. Transmission of MdSGHV among adult house flies, Musca domestica (Diptera: Muscidae), occurs via oral secretions and excreta. J Invertebr Pathol. 2009;101:49-55.

32. Geden CJ, Steenberg T, Lietze V-U, Boucias DG. Salivary gland hypertrophy virus of house flies in Denmark: prevalence, host range, and comparison with a Florida isolate. J Vector Ecol. 2011;36:231-8.

33. Vallejo C, Lee J, Keesling J, Geden C, Lietze V-U, Boucias D. A mathematic model that describes modes of MdSGHV transmission within house fly populations. Insects. 2013;4:683-93.

34. Geden C, Garcia-Maruniak A, Lietze VU, Maruniak J, Boucias DG. Impact of house fly salivary gland hypertrophy virus (MdSGHV) on a heterologous host, Stomoxys calcitrans. J Med Entomol. 2011;48:1128-35.
35. Demirbaş-Uzel G, Kariithi HM, Parker AG, Vreysen MJB, Mach RL, Abd-Alla AMM. Susceptibility of tsetse species to Glossina pallidipes salivary gland hypertrophy virus (GpSGHV). Front Microbiol. 2018;9:701.

36. Mead DG, Ramberg FB, Besselsen DG, Mare CJ. Transmission of vesicular stomatitis virus from infected to noninfected black flies co-feeding on nonviremic deer mice. Science. 2000;287:485-7.

37. FAO. In: Pollock JN, editor. Training manual for tsetse control personnel. Volume II. Ecology and behaviour of tsetse. 1st ed. Rome: Food and Agriculture Organization of the United Nations; 1982.

38. Benoit JB, Attardo GM, Baumann AA, Michalkova V, Aksoy S. Adenotrophic viviparity in tsetse flies: potential for population control and as an insect model for lactation. Annu Rev Entomol. 2015;60:351-71.

39. Tobe SS, Langley PA. Reproductive physiology of Glossina. Annu Rev Entomol. 1978;23:283-307.

40. Lewis DJ. The behaviour of the larvae of tsetse-flies before pupation. Bull Entomol Res. 1934;25:195-200.

41. Demirbaş-Uzel G, Parker AG, Vreysen MJB, Mach RL, Bouyer J, Takac P, et al. Impact of Glossina pallidipes salivary gland hypertrophy virus (GpSGHV) on a heterologous tsetse fly host, Glossina fuscipes fuscipes. BMC Microbiol. 2018; 18(Suppl 1).

42. Bull JJ, Molineux IJ, Rice WR. Selection of benevolence in a host-parasite system. Evolution. 1991;45:875-82.

43. Pagan I, Montes N, Milgroom MG, Garcia-Arenal F. Vertical transmission selects for reduced virulence in a plant virus and for increased resistance in the host. PLoS Pathog. 2014;10:e1004293.

44. Dusi E, Gougat-Barbera C, Berendonk TU, Kaltz O. Long-term selection experiment produces breakdown of horizontal transmissibility in parasite with mixed transmission mode. Evolution. 2015;69:1069-76.

45. Boldogh I, Albrecht T, Porter DD. Persistent Viral Infections. In: Baron S, editor. Med. Microbiol. 4th ed. Galveston: University of Texas Medical Branch at Galveston; 1996. p. Chapter 46

46. Abd-Alla AMM, Kariithi HM, Mohamed AH, Lapiz E, Parker AG, Vreysen MJB. Managing hytrosavirus infections in Glossina pallidipes colonies: feeding regime affects the prevalence of salivary gland hypertrophy syndrome. PLoS ONE. 2013;8:e61875.

47. Wang J, Weiss BL, Aksoy S. Tsetse fly microbiota: form and function. Front Cell Infect Microbiol. 2013;3:6

48. De Vooght L, Caljon G, Van Hees J, Van Den Abbeele J. Paternal transmission of a secondary symbiont during mating in the viviparous tsetse fly. Mol Biol Evol. 2015;32:1977-80.

49. Bahrndorff S, de Jonge N, Skovgard H, Nielsen JL. Bacterial communities associated with houseflies (Musca domestica L.) sampled within and between farms. PLOS ONE. 2017;12:e0169753.

50. Weiss BL, Wang J, Aksoy S. Tsetse immune system maturation requires the presence of obligate symbionts in larvae. PLoS Biol. 2011;9:e1000619.

51. Eleftherianos I, Atri J, Accetta J, Castillo JC. Endosymbiotic bacteria in insects: guardians of the immune system? Front Physiol. 2013;4:10.

52. Thomas P, Kenny N, Eyles D, Moreira LA, O'Neill SL, Asgari S. Infection with the wMel and wMelPop strains of Wolbachia leads to higher levels of melanization in the hemolymph of Drosophila melanogaster, Drosophila simulans and Aedes aegypti. Dev Comp Immunol. 2011;35:360-5.

53. Martinez J, Longdon B, Bauer S, Chan Y-S, Miller WJ, Bourtzis K, et al. Symbionts commonly provide broad spectrum resistance to viruses in insects: a comparative analysis of Wolbachia strains. PLoS Pathog. 2014;10:e1004369.

54. Hedges LM, Brownlie JC, O'Neill SL, Johnson KN. Wolbachia and virus protection in insects. Science. 2008;322:702.

55. Johnson K. The impact of Wolbachia on virus infection in mosquitoes. Viruses. 2015;7:5705-17.

56. Kremer N, Charif D, Henri H, Gavory F, Wincker $P$, Mavingui $P$, et al. Influence of Wolbachia on host gene expression in an obligatory symbiosis. BMC Microbiol. 2012;12:S7.

57. Pan X, Zhou G, Wu J, Bian G, Lu P, Raikhel AS, et al. Wolbachia induces reactive oxygen species (ROS)-dependent activation of the toll pathway to control denque virus in the mosquito Aedes aegypti. Proc Natl Acad Sci. 2012;109:E23-31.

58. Bian $G, X u Y, L u P, X i e Y, X i$ Z. The endosymbiotic bacterium Wolbachia induces resistance to dengue virus in Aedes aegypti. PLoS Pathog. 2010;6: e1000833.

59. Rances E, Ye YH, Woolfit M, McGraw EA, O'Neill SL. The relative importance of innate immune priming in Wolbachia-mediated dengue interference. PLOS Pathog. 2012;8:e1002548. 
60. Glaser RL, Meola MA. The native Wolbachia endosymbionts of Drosophila melanogaster and Culex quinquefasciatus increase host resistance to West Nile virus infection. PLOS ONE. 2010;5:e11977.

61. Graham Rl, Grzywacz D, Mushobozi WL, Wilson K. Wolbachia in a major African crop pest increases susceptibility to viral disease rather than protects. Ecol Lett. 2012;15:993-1000.

62. Moreira LA, Iturbe-Ormaetxe I, Jeffery JA, Lu G, Pyke AT, Hedges LM, et al. A Wolbachia symbiont in Aedes aegypti limits infection with dengue, chikungunya, and Plasmodium. Cell. 2009;139:1268-78.

63. Rancès $E$, Voronin D, Tran-Van V, Mavingui P. Genetic and functional characterization of the type IV secretion system in Wolbachia. J Bacteriol. 2008;190:5020-30

64. Dobson SL, Bourtzis K, Braig HR, Jones BF, Zhou W, Rousset F, et al. Wolbachia infections are distributed throughout insect somatic and germ line tissues. Insect Biochem Mol Biol. 1999;29:153-60.

65. Weiss BL, Maltz M, Aksoy S. Obligate symbionts activate immune system development in the tsetse fly. J Immunol. 2012;188:3395-403.

66. Cirimotich CM, Ramirez JL, Dimopoulos G. Native microbiota shape insect vector competence for human pathogens. Cell Host Microbe. 2011;10:307-10.

67. Soumana $H$, Tchicaya B, Loriod B, Rihet $P$, Geiger A. Identification of overexpressed genes in Sodalis glossinidius inhabiting trypanosome-infected self-cured tsetse flies. Front Microbiol. 2014;5:255.

68. Osborne SE, Iturbe-Ormaetxe I, Brownlie JC, O'Neill SL, Johnson KN. Antiviral protection and the importance of Wolbachia density and tissue tropism in Drosophila simulans. Appl Environ Microbiol. 2012;78:6922-9.

69. McMeniman CJ, Lane RV, Cass BN, Fong AWC, Sidhu M, Wang Y-F, et al. Stable introduction of a life-shortening Wolbachia infection into the mosquito Aedes aegypti. Science. 2009;323:141-4

70. Doudoumis V, Tsiamis G, Wamwiri F, Brelsfoard C, Alam U, Aksoy E, et al. Detection and characterization of Wolbachia infections in laboratory and natural populations of different species of tsetse flies (genus Glossina). BMC Microbiol. 2012;12:S3.

71. Doudoumis V, Alam U, Aksoy E, Abd-Alla AMM, Tsiamis G, Brelsfoard C, et al. Tsetse-Wolbachia symbiosis: comes of age and has great potential for pest and disease control. J Invertebr Pathol. 2013;112:S94-103.

72. Wamwiri FN, Alam U, Thande PC, Aksoy E, Ngure RM, Aksoy S, et al. Wolbachia, Sodalis and trypanosome co-infections in natural populations of Glossina austeni and Glossina pallidipes. Parasit Vectors. 2013;6:232.

73. Lu P, Bian G, Pan X, Xi Z. Wolbachia induces density-dependent inhibition to dengue virus in mosquito cells. PLoS Negl Trop Dis. 2012;6:e1754.

74. Teixeira L, Ferreira A, Ashburner M. The bacterial symbiont Wolbachia induces resistance to RNA viral infections in Drosophila melanogaster. PLoS Biol. 2008:6:e1000002.

75. Osborne SE, Leong YS, O'Neill SL, Johnson KN. Variation in antiviral protection mediated by different Wolbachia strains in Drosophila simulans. PLoS Pathog. 2009;5:e1000656.

76. Bourtzis K, Pettigrew MM, O'Neill SL. Wolbachia neither induces nor suppresses transcripts encoding antimicrobial peptides. Insect Mol Biol. 2000;9:635-9.

77. Zug R, Hammerstein P. Wolbachia and the insect immune system: what reactive oxygen species can tell us about the mechanisms of Wolbachiahost interactions. Front Microbiol. 2015;6:1201.

78. Lam K, Tsang M, Labrie A, Gries R, Gries G. Semiochemical-mediated oviposition avoidance by female house flies, Musca domestica, on animal feces colonized with harmful fungi. J Chem Ecol. 2010;36:141-7.

79. Romero A, Broce A, Zurek L. Role of bacteria in the oviposition behaviour and larval development of stable flies. Med Vet Entomol. 2006;20:115-21.

80. Douglas AE. The microbial dimension in insect nutritional ecology. Funct Ecol. 2009;23:38-47.

81. Ghazal P, García-Ramírez JJ, González-Armas JC, Kurz S, Angulo A. Principles of homeostasis in governing virus activation and latency. Immunol Res. 2000;21:219-23.

82. Ghazal P, González-Armas JC, García-Ramírez J, Kurz S, Angulo A. Viruses: hostages to the cell. Virology. 2000;275:233-7.

83. Walsh D, Mohr I. Viral subversion of the host protein synthesis machinery. Nat Rev Microbiol. 2011;9:860-75.

84. Lemaitre B, Hoffmann J. The host defense of Drosophila melanogaster. Annu Rev Immunol. 2007;25:697-743

85. Tzou P, De Gregorio E, Lemaitre B. How Drosophila combats microbial infection: a model to study innate immunity and host-pathogen interactions. Curr Opin Microbiol. 2002;5:102-10.
86. Tzou P, Ohresser S, Ferrandon D, Capovilla M, Reichhart J-M, Lemaitre B, et al. Tissue-specific inducible expression of antimicrobial peptide genes in Drosophila surface epithelia. Immunity. 2000;13:737-48.

87. Galiana-Arnoux D, Dostert C, Schneemann A, Hoffmann JA, Imler J-L. Essential function in vivo for Dicer-2 in host defense against RNA viruses in Drosophila. Nat Immunol. 2006;7:590-7.

88. van Rij RP, Saleh MC, Berry B, Foo C, Houk A, Antoniewski C, et al. The RNA silencing endonuclease Argonaute 2 mediates specific antiviral immunity in Drosophila melanogaster. Genes Dev. 2006;20:2985-95.

89. Zambon RA, Vakharia VN, Wu LP. RNAi is an antiviral immune response against a dsRNA virus in Drosophila melanogaster. Cell Microbiol. 2006;8: 880-9.

90. Xi Z, Ramirez JL, Dimopoulos G. The Aedes aegypti toll pathway controls dengue virus infection. PLoS Pathog. 2008;4:e1000098.

91. Dostert C, Jouanguy E, Irving P, Troxler L, Galiana-Arnoux D, Hetru C, et al. The Jak-STAT signaling pathway is required but not sufficient for the antiviral response of Drosophila. Nat Immunol. 2005:6:946-53.

92. Avadhanula V, Weasner BP, Hardy GG, Kumar JP, Hardy RW. A novel system for the launch of alphavirus RNA synthesis reveals a role for the Imd pathway in arthropod antiviral response. PLoS Pathog. 2009;5:e1000582.

93. Costa A, Jan E, Sarnow P, Schneider D. The Imd pathway is involved in antiviral immune responses in Drosophila. PLOS ONE. 2009;4:e7436.

94. Kariithi HM, Ince Al, Boeren S, Murungi EK, Meki IK, Otieno EA, et al. Comparative analysis of salivary gland proteomes of two Glossina species that exhibit differential hytrosavirus pathologies. Front Microbiol. 2016;7:89.

95. Kariithi HM, van Lent JW, Boeren S, Abd-Alla AM, Ince Al, van Oers MM, et al. Correlation between structure, protein composition, morphogenesis and cytopathology of Glossina pallidipes salivary gland hypertrophy virus. J Gen Virol. 2013;94:193-208.

96. Kariithi HM, Ince IA, Boeren S, Abd-Alla AMM, Parker AG, Aksoy S, et al. The salivary secretome of the tsetse fly, Glossina pallidipes (Diptera: Glossinidae) infected by salivary gland hypertrophy virus. PLoS Negl Trop Dis. 2011:5:e1371.

97. Chaston TB, Lidbury BA. Genetic "budget" of viruses and the cost to the infected host: a theory on the relationship between the genetic capacity of viruses, immune evasion, persistence and disease. Immunol Cell Biol. 2001; 79:62-6.

98. Lucas M, Karrer URS, Lucas A, Klenerman P. Viral escape mechanismsescapology taught by viruses. Int J Exp Pathol. 2001:82:269-86.

99. Burand JP, Hunter WB. RNAi: Future in insect management. J Invertebr Pathol. 2013;112:S68-74.

100. Bronkhorst AW, van Cleef KW, Vodovar N, Ince IA, Blanc H, Vlak JM, et al. The DNA virus invertebrate iridescent virus 6 is a target of the Drosophila RNAi machinery. Proc Natl Acad Sci U S A. 2012;109:E3604-13.

101. Li F, Ding SW. Virus counterdefense: diverse strategies for evading the RNAsilencing immunity. Annu Rev Microbiol. 2006:60:503-31.

102. Wang XH, Aliyari R, Li WX, Li HW, Kim K, Carthew R, et al. RNA interference directs innate immunity against viruses in adult Drosophila. Sci Wash DC. 2006;312:452-4

103. Meki IK, Kariithi HM, Ince IA, Boucias DG, Vlak JM, van Oers MM, et al. Interactions between the salivary gland hypertrophy virus and its hos immune system, 49th Annu. Meet. Soc. Invertebr. Pathol. Vinci Centre international de Congrès, Tours, France: Society for Invertebrate Pathology; 2016. p. 70

104. Guo YE, Steitz JA. Virus meets host microRNA: the destroyer, the booster, the hijacker. Mol Cell Biol. 2014:34:3780-7.

105. Cullen BR. Viral and cellular messenger RNA targets of viral microRNAs. Nature. 2009:457:421-5.

106. Pfeffer S, Sewer A, Lagos-Quintana M, Sheridan R, Sander C, Grasser FA, et al. Identification of microRNAs of the herpesvirus family. Nat Methods. 2005:2:269-76

107. Gottwein E, Mukherjee N, Sachse C, Frenzel C, Majoros WH, Chi J-TA, et al. A viral microRNA functions as an orthologue of cellular miR-155. Nature. 2007; 450:1096-9.

108. Boss IW, Renne R. Viral miRNAs: tools for immune evasion. Curr Opin Microbiol. 2010;13:540-5

109. Lieberman PM. Epigenetics and genetics of viral latency. Cell Host Microbe. 2016;19:619-28

110. Lu F, Stedman W, Yousef M, Renne R, Lieberman PM. Epigenetic regulation of Kaposi's sarcoma-associated herpesvirus latency by virus-encoded MicroRNAs that target Rta and the cellular Rbl2-DNMT pathway. J Virol. 2010:84:2697-706. 
111. Grundhoff A, Sullivan CS. Virus-encoded microRNAs. Virology. 2011;411:325-43.

112. Everett $H$, McFadden $G$. Apoptosis: an innate immune response to virus infection. Trends Microbiol. 1999;7:160-5.

113. Nainu F, Tanaka Y, Shiratsuchi A, Nakanishi Y. Protection of insects against viral infection by apoptosis-dependent phagocytosis. J Immunol. 2015;195: 5696-706.

114. Yoo SJ, Huh JR, Muro I, Yu H, Wang L, Wang SL, et al. Hid, Rpr and Grim negatively regulate DIAP1 levels through distinct mechanisms. Nat Cell Biol. 2002:4:416-24

115. Roulston A, Marcellus RC, Branton PE. Viruses and apoptosis. Annu Rev Microbiol. 1999:53:577-628.

116. Teodoro JG, Branton PE. Regulation of apoptosis by viral gene products. J Virol. 1997:71:1739.

117. Cooper DM, Granville DJ, Lowenberger C. The insect caspases. Apoptosis. 2009:14:247-56.

118. Lamkanfi M. Alice in caspase land. A phylogenetic analysis of caspases from worm to man. Cell Death Differ. 2002;9:358-61.

119. Hay BA, Guo M. Caspase-dependent cell death in Drosophila. Annu Rev Cell Dev Biol. 2006:22:623-50

120. Li J, Yuan J. Caspases in apoptosis and beyond. Oncogene. 2008;27: 6194-206.

121. Foley $\mathrm{E}, \mathrm{O}^{\prime}$ Farrell $\mathrm{PH}$. Functional dissection of an innate immune response by a genome-wide RNAi screen. PLoS Biol. 2004;2:e203.

122. Benedict CA, Norris PS, Ware CF. To kill or be killed: viral evasion of apoptosis. Nat Immunol. 2002;3:1013-8.

123. Clem RJ. Baculoviruses and apoptosis: the good, the bad, and the ugly. Cell Death Differ. 2001;8:137-43.

124. Prikhod'ko GG, Wang Y, Freulich E, Prives C, Miller LK. Baculovirus p33 binds human p53 and enhances p53-mediated apoptosis. J Virol. 1999;73:1227-34

125. Clarke TE, Clem RJ. Insect defenses against virus infection: the role of apoptosis. Int Rev Immunol. 2003;22:401-24.

126. Mehrabadi M, Hussain M, Matindoost $L$, Asgari $S$. The baculovirus antiapoptotic p35 protein functions as an inhibitor of the host RNA interference antiviral response. J Virol. 2015:89:8182-92.

127. Ikeda M, Yamada H, Hamajima R, Kobayashi M. Baculovirus genes modulating intracellular innate antiviral immunity of lepidopteran insect cells. Virology. 2013;435:1-13.

128. Yang YL, Li XM. The IAP family: endogenous caspase inhibitors with multiple biological activities. Cell Res. 2000;10:169.

129. Chai J, Yan N, Huh JR, Wu J-W, Li W, Hay BA, et al. Molecular mechanism of Reaper-Grim-Hid-mediated suppression of DIAP1-dependent Dronc ubiquitination. Nat Struct Biol. 2003;10:892-8.

130. Shi Y. Caspase activation, inhibition, and reactivation: a mechanistic view. Protein Sci. 2004;13:1979-87.

131. Best SM. Viral subversion of apoptotic enzymes: escape from death row. Annu Rev Microbiol. 2008;62:171-92.

132. Miele SAB, Garavaglia MJ, Belaich MN, Ghiringhelli PD. Baculovirus: molecular insights on their diversity and conservation. Int J Evol Biol. 2011 2011:379424.

133. Slack J, Arif BM. The baculoviruses occlusion-derived virus: virion structure and function. Adv Virus Res. 2007;69:99-165.

134. Raftery M, Müller A, Schönrich G. Herpesvirus homologues of cellular genes. Virus Genes. 2000;21:65-75.

135. Tidona CA, Darai G. Iridovirus homologues of cellular genes-implications for the molecular evolution of large DNA viruses. Virus Genes. 2000:21:77-81.

136. Spencer JV, Lockridge KM, Barry PA, Lin G, Tsang M, Penfold MET, et al. Potent immunosuppressive activities of cytomegalovirus- encoded interleukin-10. J Virol. 2002;76:1285-92.

137. Hughes AL. Evolution of inhibitors of apoptosis in baculoviruses and their insect hosts. Infect Genet Evol. 2002;2:3-10.

138. Filée J. Multiple occurrences of giant virus core genes acquired by eukaryotic genomes: the visible part of the iceberg? Virology. 2014;466-467: 53-9.

139. Filée J, Forterre P. Viral proteins functioning in organelles: a cryptic origin? Trends Microbiol. 2005;13:510-3.

140. Tanji T, Hu X, Weber ANR, Ip YT. Toll and IMD pathways synergistically activate an innate immune response in Drosophila melanogaster. Mol Cell Biol. 2007:27:4578-88.

141. Strand MR. The insect cellular immune response. Insect Sci. 2008;15:1-14.

142. Janeway CAJ. Approaching the asymptote? Evolution and revolution in immunology. Cold Spring Harb Symp Quant Biol. 1989;54:1-13.
143. Kim CH, Shin YP, Noh MY, Jo YH, Han YS, Seong YS, et al. An insect multiligand recognition protein functions as an opsonin for the phagocytosis of microorganisms. J Biol Chem. 2010;285:25243-50.

144. Prasad A, Brackney D, Ebel G. The role of innate immunity in conditioning mosquito susceptibility to West Nile virus. Viruses. 2013;5:3142-70.

145. An C, Jiang $H$, Kanost MR. Proteolytic activation and function of the cytokine Spätzle in the innate immune response of a lepidopteran insect, Manduca sexta. FEBS J. 2010;277:148-62.

146. Kanost MR, Jiang H. Clip-domain serine proteases as immune factors in insect hemolymph. Curr Opin Insect Sci. 2015;11:47-55.

147. Christensen BM, Li J, Chen C-C, Nappi AJ. Melanization immune responses in mosquito vectors. Trends Parasitol. 2005;21:192-9.

148. Popham HJR. Potent virucidal activity in larval Heliothis virescens plasma against Helicoverpa zea single capsid nucleopolyhedrovirus. J Gen Virol. 2004:85:2255-61.

149. Shelby KS, Popham HJ. Plasma phenoloxidase of the larval tobacco budworm, Heliothis virescens, is virucidal. J Insect Sci. 2006:6:13.

150. Zhao P, Lu Z, Strand MR, Jiang H. Antiviral, anti-parasitic, and cytotoxic effects of 5,6-dihydroxyindole $(\mathrm{DHI})$, a reactive compound generated by phenoloxidase during insect immune response. Insect Biochem Mol Biol. 2011:41:645-52.

151. Tamang D, Tseng SM, Huang CY, Tsao IY, Chou SZ, Higgs S, et al. The use of a double subgenomic Sindbis virus expression system to study mosquito gene function: effects of antisense nucleotide number and duration of viral infection on gene silencing efficiency. Insect Mol Biol. 2004;13:595-602.

152. Rodriguez-Andres J, Rani S, Varjak M, Chase-Topping ME, Beck MH, Ferguson MC, et al. Phenoloxidase activity acts as a mosquito innate immune response against infection with Semliki Forest virus. PLoS Pathog. 2012:8:e1002977.

153. Obbard DJ, Dudas G. The genetics of host-virus coevolution in invertebrates. Curr Opin Virol. 2014:8:73-8.

154. Obbard DJ, Jiggins FM, Bradshaw NJ, Little TJ. Recent and recurrent selective sweeps of the antiviral RNAi gene argonaute- 2 in three species of Drosophila. Mol Biol Evol. 2011;28:1043-56.

155. Pal-Bhadra M, Leibovitch BA, Gandhi SG, Chikka MR, Bhadra U, Birchler JA et al. Heterochromatic silencing and HP1 localization in Drosophila are dependent on the RNAi machinery. Science. 2004;303:669-72

156. Kennerdell JR, Yamaguchi S, Carthew RW. RNAi is activated during Drosophila oocyte maturation in a manner dependent on aubergine and spindle-E. Genes Dev. 2002;16:1884-9.

157. Obbard DJ, Gordon $\mathrm{KH}$, Buck AH, Jiggins FM. The evolution of RNAi as a defence against viruses and transposable elements. Philos Trans R Soc B Biol Sci. 2009;364:99-115.

158. Meister G. Argonaute proteins: functional insights and emerging roles. Nat Rev Genet. 2013;14:447-59.

159. Hammond SM. Dicing and slicing: the core machinery of the RNA interference pathway. FEBS Lett. 2005;579:5822-9.

160. Haac ME, Anderson MAE, Eggleston H, Myles KM, Adelman ZN. The hub protein loquacious connects the microRNA and short interfering RNA pathways in mosquitoes. Nucleic Acids Res. 2015:43:3688-700.

161. Waterhouse RM, Kriventseva EV, Meister S, Xi Z, Alvarez KS, Bartholomay LC, et al. Evolutionary dynamics of immune-related genes and pathways in disease-vector mosquitoes. Science. 2007:316:1738-43.

162. Giraldo-Calderón Gl, Emrich SJ, MacCallum RM, Maslen G, Dialynas E, Topalis $P$, et al. VectorBase: an updated bioinformatics resource for invertebrate vectors and other organisms related with human diseases. Nucleic Acids Res. 2015;43:D707-13.

163. Finn RD, Coggill $P$, Eberhardt RY, Eddy SR, Mistry J, Mitchell AL, et al. The Pfam protein families database: towards a more sustainable future. Nucleic Acids Res. 2016;44:D279-85.

164. Brucker RM, Funkhouser LJ, Setia S, Pauly R, Bordenstein SR. Insect innate immunity database (IIID): an annotation tool for identifying immune genes in insect genomes. PLoS ONE. 2012;7:e45125.

165. Katoh K, Standley DM. MAFFT multiple sequence alignment software version 7: improvements in performance and usability. Mol Biol Evol. 2013; 30:772-80.

166. Waterhouse AM, Procter JB, Martin DMA, Clamp M, Barton GJ. Jalview version 2-a multiple sequence alignment editor and analysis workbench. Bioinformatics. 2009:25:1189-91.

167. Guindon S, Dufayard J-F, Lefort V, Anisimova M, Hordijk W, Gascuel O. New algorithms and methods to estimate maximum-likelihood phylogenies: assessing the performance of PhyML 3.0. Syst Biol. 2010;59:307-21. 
168. Ronquist F, Teslenko M, van der Mark P, Ayres DL, Darling A, Höhna S, et al. MrBayes 3.2: efficient Bayesian phylogenetic inference and model choice across a large model space. Syst Biol. 2012;61:539-42.

169. Letunic I, Bork P. Interactive tree of life (iTOL) v3: an online tool for the display and annotation of phylogenetic and other trees. Nucleic Acids Res. 2016:44:W242-5.

170. Lee J-C, Chen H-H, Chao Y-C. Persistent baculovirus infection results from deletion of the apoptotic suppressor gene p35. J Virol. 1998;72:9157-65.

171. Manji GA, Hozak RR, LaCount DJ, Friesen PD. Baculovirus inhibitor of apoptosis functions at or upstream of the apoptotic suppressor P35 to prevent programmed cell death. J Virol. 1997;71:4509-16.

172. Huang Q, Deveraux QL, Maeda S, Salvesen GS, Stennicke HR, Hammock BD, et al. Evolutionary conservation of apoptosis mechanisms: lepidopteran and baculoviral inhibitor of apoptosis proteins are inhibitors of mammalian caspase-9. Proc Natl Acad Sci. 2000;97:1427-32.

173. Wang SL, Hawkins CJ, Yoo SJ, Muller HA, Hay BA. The Drosophila caspase inhibitor DIAP1 is essential for cell survival and is negatively regulated by HID. Cell. 1999;98:453-63.

174. Kingsolver MB, Huang Z, Hardy RW. Insect antiviral innate immunity: pathways, effectors, and connections. J Mol Biol. 2013;425:4921-36.

Ready to submit your research? Choose BMC and benefit from:

- fast, convenient online submission

- thorough peer review by experienced researchers in your field

- rapid publication on acceptance

- support for research data, including large and complex data types

- gold Open Access which fosters wider collaboration and increased citations

- maximum visibility for your research: over $100 \mathrm{M}$ website views per year

At $B M C$, research is always in progress.

Learn more biomedcentral.com/submissions 